\title{
La necrópolis celtibérica del Inchidero (Aguilar de Montuenga, Soria): Estratigrafía, cronotipología y dataciones radiocarbónicas
}

\section{The Celtiberian Cemetery of Inchidero (Aguilar de Montuenga, Soria): Stratigraphy, Chrono-Typology and Radiocarbon Dating}

\author{
Marian ArLegui SÁNChez \\ Museo Numantino. Paseo del Espolón 8, 42001 Soria \\ arlsanma@jcyl.es
}

Recibido: 25-04-2012

Aceptado: 08-06-2012

\section{RESUMEN}

Esta necrópolis celtibérica del Alto Jalón, aún en proceso de estudio, ha deparado una estratigrafía horizontal y vertical que junto a la cronotipología de los materiales y las fechas radiocarbónicas obtenidas, presentadas aqui para su discusión, permiten establecer una secuencia evolutiva más compleja y actualizada que la disponible hasta el momento, procedente de excavaciones de comienzos del siglo XX, sobre el período representativo de la necrópolis, entre finales del siglo VI y el siglo III a.C.

Palabras Clave: Estratigrafía. Cronotipología. Carbono 14. Necrópolis celtibéricas. Alto Jalón. Soria.

\begin{abstract}
This Celtiberian cemetery from the Upper Jalón river, which is still under excavation and analysis, offered interesting data about horizontal and vertical stratigraphy which allows, together with the chrono-typology of the archaeological materials and the radio-carbon dates presented here for discussion, to establish a more complex and up-to-date cultural sequence than the previously available, mostly coming from excavations made at the beginning of the $20^{\text {th }}$ century, about the Celtiberian period represented in the site, i.e. form the late $6^{\text {th }}$ century to the $3^{\text {rd }}$ century BC.
\end{abstract}

KEY wORDs: Stratigraphy. Chrono-typology. Radiocarbon dating. Celtiberian Cemeteries. Upper Jalon River. Soria.

Sumario 1. Introducción. 1.1. El poblado y la necrópolis en su contexto geográfico. 1.2. Situación y extensión de la necrópolis. 1.3. Orientación general de la necrópolis. Disposición de las tumbas. 2. Estratigrafía horizontal y vertical. Correlaciones estratigráficas. 2.1. Una reflexión inicial. 2.2. La estratigrafía. Relaciones sincrónicas y diacrónicas. 3. Seriación tipológica de los materiales. 4. Las dataciones radiocarbónicas. 5. Conclusiones. 


\section{Introducción}

\subsection{El poblado y la necrópolis en su contexto geográfico}

La realización de trabajos de desmonte en el lado sur de la ladera del actual pueblo de Aguilar de Montuenga (Soria) para la construcción de una nave dejó al descubierto una importante necrópolis de la Edad del Hierro (Fig. 1). La notificación de los hallazgos puso en marcha el proceso administrativo que condujo a una excavación arqueológica de urgencia para su correspondiente evaluación ${ }^{1}$. La excavación afectó una superficie de $30,50 \mathrm{~m}^{2}$ y puso al descubierto un total de 37 enterramientos de los que seis están descontextualizados o profundamente alterados (Fig. 2). El sitio, conocido como El Inchidero, se sitúa en el Alto Jalón, en un punto equidistante entre los arroyos Sagides y Chaorna que discurren de Sur a Norte. El primero de ellos

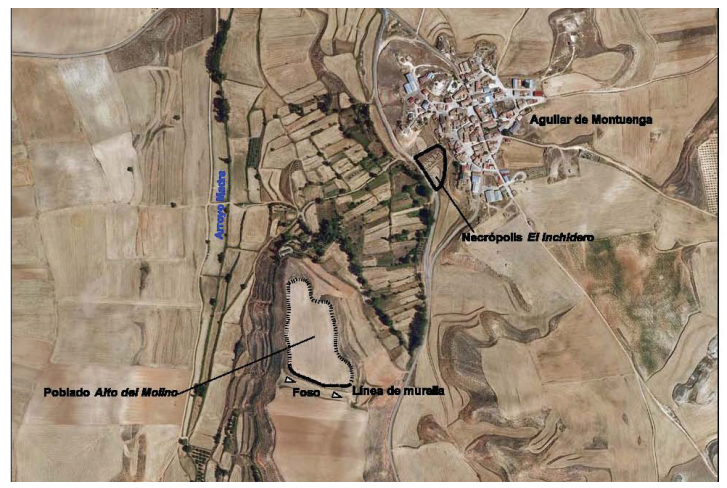

Figura 1.- Situación de la necrópolis y el poblado en el pueblo de Aguilar de Montuenga.

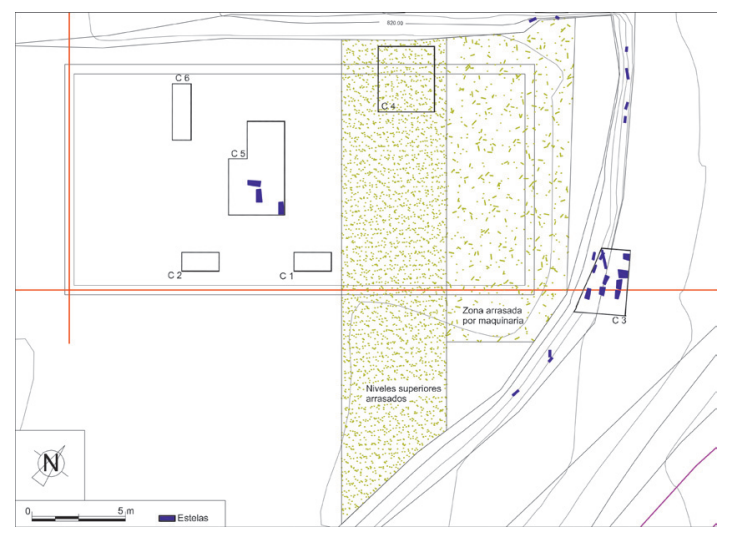

Figura 2.- Situación de las calicatas excavadas y niveles de arrasamiento por maquinaria de la zona estudiada. recorre el valle Oeste del Alto del Molino, poblado al que adscribimos la necrópolis. En el lado este del poblado, traspasando la actual vega y en ladera, como es habitual, se dispuso la necrópolis. Esta ladera, en origen menos pronunciada que en la actualidad, debía elevarse bruscamente a espaldas de la necrópolis. Al este del municipio, situado sobre la necrópolis, corre el arroyo Chaorna. Ambos afluentes desembocan en el Jalón a menos de $2 \mathrm{~km}$.

El poblado del Alto del Molino de Aguilar de Montuenga, de 2,5 Ha de superficie en la actualidad, es un espigón de planta triangular. Una importante cresta de sección triangular revela la existencia de una muralla ante la que se dispuso un foso de considerable anchura de donde, sin duda, procede la piedra para la construcción de aquélla. Resulta claro que las casas se dispusieron perimetralmente. Corresponde en sus aspectos arquitectónicos, tanto defensivos como habitacionales, al mismo tipo y cronología que Castilmontán en Somaén (Arlegui 1992).

Morfológicamente el yacimiento se sitúa en la zona donde el río Jalón, tras discurrir encajado por medio de profundas hoces y atravesar una zona sedimentaria, en una acción erosiva muy importante, se abre al valle que cruza el Sistema Ibérico. La necrópolis y el poblado de Aguilar se encuentran justo en el punto donde el Jalón abandona la hoz y se extiende en dirección a Ariza. Se trata de un territorio de cereal y productos de huerta junto a los arroyos, y de ganadería ovina en la próxima Sierra de Solorio.

El relieve, una vez que el río abandona el cañón en las proximidades de Arcos de Jalón, ofrece alturas relativas y mesetas con marcado carácter de horizontalidad, formando niveles de conglomerado y de arenas y yesos. Ello produce un paisaje determinante en la localización de yacimientos. Los procesos erosivos, debidos a la fuerte deforestación histórica de la zona, depositan en las laderas y en los valles las rocas fracturadas de las capas duras de conglomerado; sobre ellas la continua erosión de las capas blandas acumula materiales en el valle creando laderas de mayor pendiente cuanto mayor es la erosión. Sin ninguna duda este factor condiciona seriamente nuestra aprehensión del paisaje antiguo. El Jalón constituye una anomalía dentro del Sistema Ibérico, un paisaje de ricas vegas y abundante agua donde la permeabilidad del suelo facilita una extensa circulación subterránea que carga las aguas de elementos minerales, como los salinos, que dieron fama a la región en el templado del acero o el curtido de pieles. Por influjo del clima mediterráneo y su menor altitud respecto a la meseta, se producen importantes estiajes en verano. 
Un aspecto importante en el desarrollo cultural de esta zona es sin duda la presencia de mineral de hierro (Madroñero y Arlegui 1992). Las mineralizaciones de tipo kárstico constituyen un horizonte ferruginoso más o menos regular a lo largo de 2,5 $\mathrm{Km}$. al NO de la carretera N-2. Al SE la potencia es mayor pero sin aquella continuidad de afloramiento. Está formada por goethita-limonita bastante pura, laminada frecuentemente y depositada sobre un paleorrelieve muy karstificado que se desarrolla sobre distintas unidades: facies Muschelkalk, facies Keuper o Lías. Existen inyecciones de gel de hierro en los conglomerados miocenos (SIEMCALSA 1997). A diferencia del distrito del Moncayo, donde los afloramientos de metal son filonianos, en esta zona son estratiformes (IGME 1973). En cualquier caso, es algo ya repetido la importancia que estos afloramientos de hierro debieron tener en la organización territorial y social de los pueblos celtibéricos de estas áreas a través de un aprovechamiento articulado y planificado. La sal en Salinas de Medinaceli y en los pueblos próximos de Guadalajara, Imón o Sigüenza, explotados históricamente, tuvo asimismo una importancia señalada en la Edad del Hierro (Ruiz-Gálvez 1990).

\subsection{Situación y extensión de la necrópolis}

La necrópolis se encuentra a $850 \mathrm{~m}$ del poblado medidos desde el vértice (al norte) de este último. Entre ambos existe hoy una vega creada por la desviación artificial, en el siglo pasado, que parte del cauce del río Sagides o Madre que discurre en el lado oeste del poblado. No descartamos que en el momento de uso de la necrópolis existiera un arroyo de escaso caudal y flujo intermitente o alguna fuente, hoy desaparecidos, entre la necrópolis y el poblado. No nos detendremos en el significado de la proximidad del agua en las necrópolis celtibéricas, hecho que ya fue realzado por Cerralbo cuando observara que se encontraban cerca de ríos y fuentes así como de pozos salados (Aguilera 1916: 9). El camino al poblado debía de discurrir entre el poblado y la necrópolis.

La extensión y por tanto la delimitación exacta de la necrópolis resulta algo aventurada. La ladera tiene una potente capa de sedimentación que nos impidió detectar algún vestigio más allá de las estelas situadas en el lado sur del anfiteatro. De otro lado, el pueblo de Aguilar ha generado vertidos hacia la ladera, lo que dificultaría una prospección geomagnética. No obstante, la disposición de las tumbas sigue un patrón de orientación genérico de noreste a suroeste, o viceversa; y en todas aquellas necrópolis en las que se ha documentado su ex- tensión total, la forma es de tendencia rectangular. Igualmente creemos que la necrópolis no se extendiera sobre la vega ya que si, como parece, esa fue zona de inundación, la necrópolis quedaría en un nivel superior, en la primera terraza. Para el lado sur hemos considerado como límite la línea que cierra ese anfiteatro. En el lado norte, la razón de la línea trazada responde a lo que creemos extensión máxima posible.

Con estas salvedades, la extensión de la necrópolis sería de $3976,53 \mathrm{~m}^{2}$ (83 $\left.\mathrm{m} \times 47,91 \mathrm{~m}\right)$, que podemos comparar de forma tentativa con los conocidos para otros cementerios de la época: Aguilar de Anguita, con $11821 \mathrm{~m}^{2}$ (Aguilera 1916: 10), Numancia, $10000 \mathrm{~m}^{2}$ (Jimeno 1996: 58), La Riba de Saelices, $5000 \mathrm{~m}^{2}$ (Cuadrado 1968: 9), la Mercadera, $1500 \mathrm{~m}^{2}$ (Lorrio 1990: 39) o La Requijada de Gormaz, $2750 \mathrm{~m}^{2}$.

\subsection{Orientación general de la necrópolis. Dispo- sición de las tumbas}

La necrópolis marca una intencionada disposición en las alineaciones de tumbas (Figs. 2 y 3 ) y en el trazado de las calles de estelas (Fig. 4 y 6 ) que difiere, por ejemplo, de la necrópolis de Herrería (Cerdeño y Sagardoy 2007). Sin duda un estudio más amplio sobre la orientación de las necrópolis sería determinante a la hora de considerar las razones que llevaron a ello, si fueron de índole astronómica -referencia a un origen o destino mítico-, geográfica o si depende sencillamente del momento de fundación de la necrópolis, que sin duda tuvo que ser ceremonial.
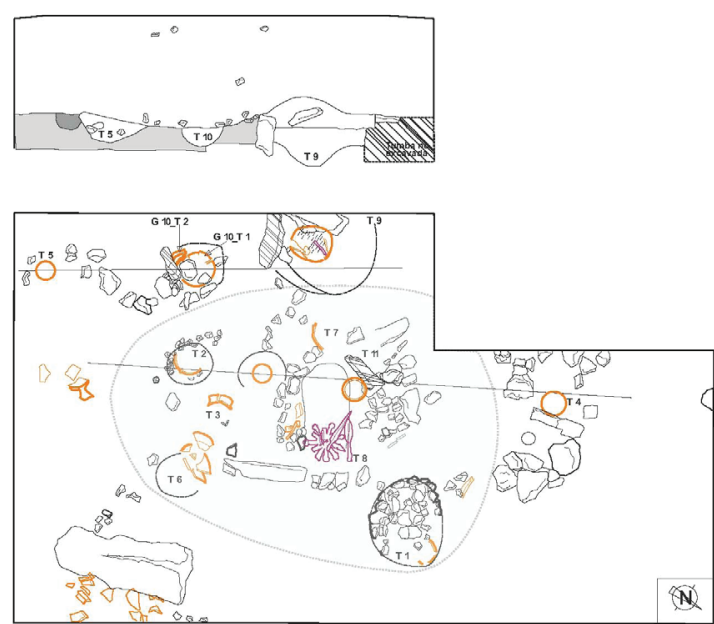

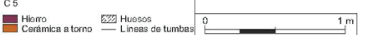

Figura 3.- C5. Dos alineaciones de tumbas y sección vertical de una de ellas. 


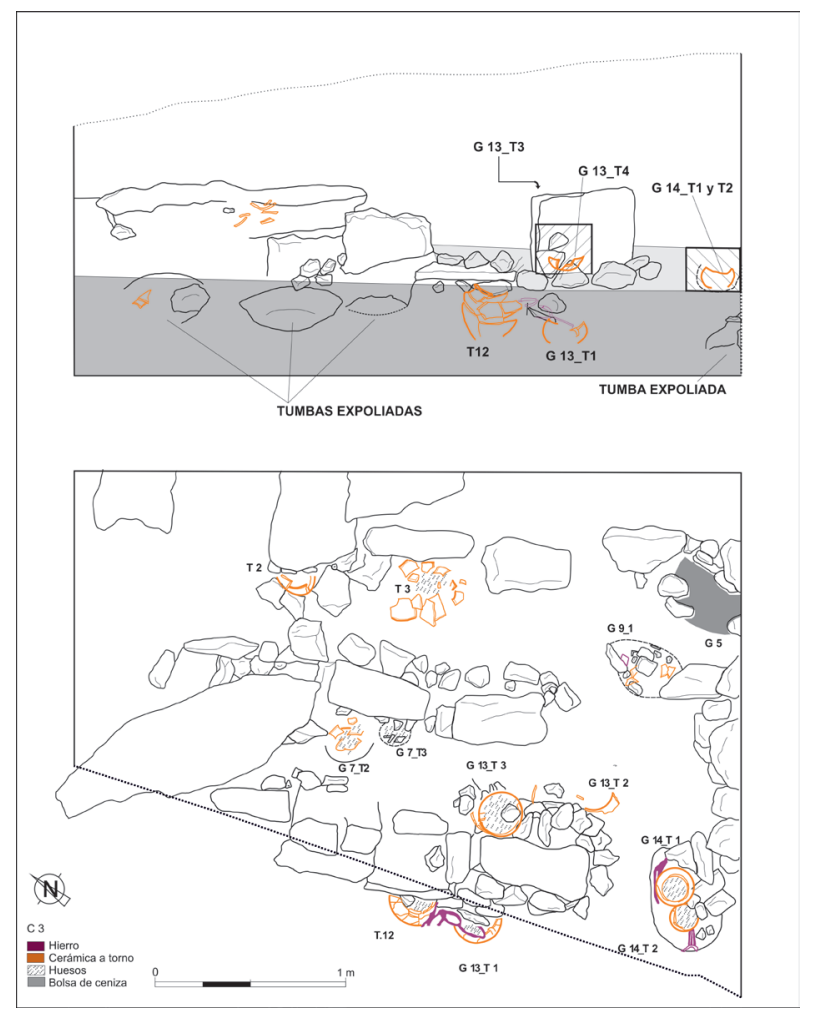

Figura 4.- C3. Situación de las tumbas y perfil donde se indica, en oscuro, la primera fase, y en más claro la segunda. La tumba G14T1-T2 es intermedia estratigráficamente. La C3G13T4 corresponde a la tercera y última fase.

En todos los casos documentados los restos óseos fueron depositados en urna y ésta, bien en fosa o semienterrada, fue cubierta con tierra y piedras o señalizada con estela. No hemos encontrado evidencias de ustrina. La disposición de las urnas es muy variada dentro de su correspondiente alineación o estela: en el área C3, las urnas T12 y G13 T1

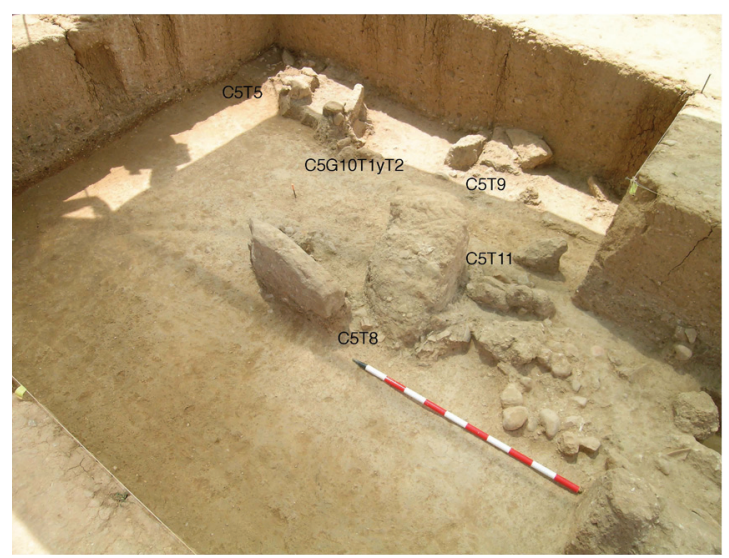

Figura 5.- C5. Tumbas de la primera y segunda fase, retiradas las de la tercera. se disponen en la cara oeste de la estela al igual que G7T1-2-3. Los enterramientos superiores al G13, sin embargo, se dispusieron en el lado este de la estela en sus vértices norte y sur; en el C5, las lajas orientaron las urnas al este en la T9, al oeste la T4, y hacia el sureste la T11. No creemos que todas estas elecciones carecieran de sentido.

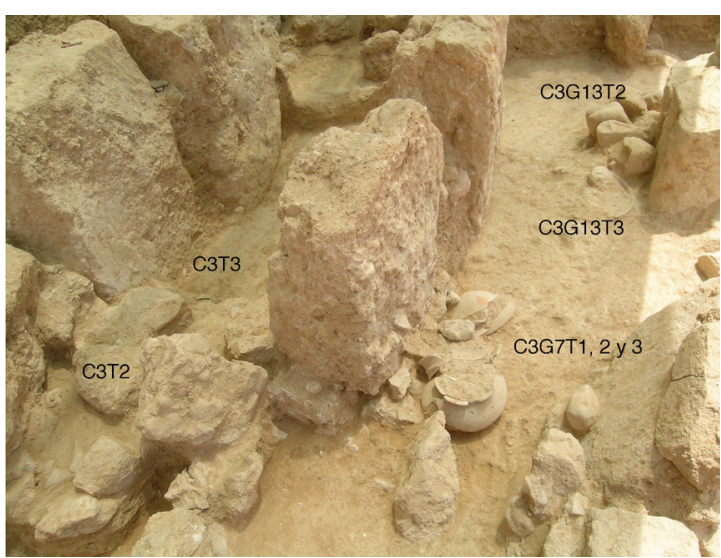

Figura 6.- C3. Calles de estelas. 
Existen dos áreas claramente diferenciadas en el sector que fue excavado: calles de estelas en el área este (C3) (Figs. 4 y 6) y alineaciones de tumbas en el resto (C5 y C6) (3s. 2 y 5). No obstante hallamos 3 estelas en C5, dos desplazadas ya de antiguo de su ubicación original y otra caída pero in situ. Como detallaremos más adelante existe una diferencia cronológica importante. Creemos que, en origen, la necrópolis fue de sepulturas alineadas y posteriormente se reordenó y creció con un esquema de calles de estelas. No podemos asegurar que existan espacios intermedios libres de tumbas. Sin embargo, hemos de señalar que las catas 1 y 2 fueron estériles y que en la cata 5 existe una zona libre de enterramientos.

\section{Estratigrafía horizontal y vertical. Correlaciones estratigráficas}

\subsection{Una reflexión inicial}

Para establecer la cronología de la necrópolis y su proceso evolutivo contamos con la evidencia estratigráfica, el estudio cronotipológico de los materiales y de los sistemas de enterramiento, y las fechas radiocarbónicas, cuya aplicación requiere análisis y discusión. Obviamente los datos estratigráficos necesitan unas coordenadas cronológicas que por si mismos no tienen, lo que nos lleva a una secuencia cronológica relativa; de otro lado, el estudio tipológico tiene fuertes limitaciones a causa de las perduraciones y localismos, pero al mismo tiempo puede proveer series muy detalladas. No podemos olvidar que gran parte del sistema comparativo celtibérico se basa en los hallazgos de excavaciones antiguas que se fecharon entre los siglos V y III a.C., reconociendo una única fase, basado en un concepto difusionista y donde las escalas de avance de las innovaciones, siempre desde el Levante o el Sur de Francia, se fijaron convencionalmente.

Respecto a las estructuras funerarias, no existe un estudio que analice las variantes y su evolución comparativamente por áreas. El enterramiento en fosa o semifosa que hemos encontrado en El Inchidero es una constante a lo largo de la cultura celtibérica; la alineación de tumbas como ordenación del espacio funerario tiene cronologías variadas; la ordenación mediante calles de estelas o el uso individualizado de las mismas difiere en el tiempo, cubriendo un espacio que abarca desde el Celtibérico Antiguo (Herrería I) al Celtibérico Tardio (La Riba de Saelices), con ejemplos más numerosos en el Celtibérico Pleno (Aguilar de Anguita, Luzaga, Hortezuela de Océn, Torresabiñán, Clarés, La Olmeda, Valdenovillos...).
Los márgenes temporales que ofrecen los estudios de los materiales, incluso los más precisos, son de dos siglos, tanto en muchos modelos de fíbulas (cuya oscilación cronológica es aún más severa) como también en los tipos cerámicos. En el caso de estos últimos creímos inútil, salvo excepciones, basarnos en paralelos con yacimientos que no son estrictamente de nuestra área (Ato Tajo-Alto Jalón) porque creemos que distanciarnos de la zona de estudio aleja en progresión geométrica la posibilidad de una correlación acertada. Tampoco existe un análisis que sistematice las formas cerámicas por áreas, excepto el estudio de García Huerta (1990), al que habrán de incorporarse los nuevos hallazgos. De manera que, incluso cruzando los datos cronológicos deparados por la tipología de los objetos hallados, incluidos los enterramientos más numerosos, nos encontramos con una atribución genérica en "fases" amplias, cuyos límites inferior y superior siempre quedan difusos. A ello ha de sumarse que, de las excavaciones recientes, en pocas ocasiones contamos con fechas obtenidas por métodos de datación absoluta. En este estado de la investigación no es posible discernir la pervivencia de materiales, las diferencias culturales locales y su desarrollo interno o la posible procedencia foránea (más allá del comercio) de algunas de las piezas. Sólo llegamos a valoraciones genéricas, a una falsa apariencia de homogeneidad, demasiado sencilla para un proceso cultural tan complejo como el llevado a cabo en aquellos siglos.

Por otro lado, hoy están en uso varios sistemas de denominación y definición de las fases de la cultura celtibérica. Desde la que se basa en los estudios de la cultura ibérica, ofreciendo por ello una división en Celtibérico Antiguo, Pleno, Tardío y Celtibero-Romano, hasta la que desborda el marco de la Edad del Hierro para fijar el inicio de esta cultura: Protoceltibérico (Bronce Final), Celtibérico Antiguo, Pleno y Tardio. Otros autores prefieren hablar de fases (I y II) y subfases (Lorrio 2005) según las áreas geográficas (Alto Tajo-Alto Jalón y Alto Duero). Esta categoría se basa en un documentado estudio tipológico. En general haremos referencia a la sistematización de Lorrio (1995 y 2005) ya que, en algunos casos, las restantes periodizaciones se ajustan a cronologías y divisiones particulares de cada yacimiento, lo que enredaría la asignación de fechas. La periodización seguida por Arenas (1999) para los estudios de la comarca de Molina de Aragón es afín a la de Lorrio, si bien no define con claridad el final del Celtibérico Pleno B. Para el estudio del área entre los ríos Jalón y Mesa, Martínez Naranjo (1997) siguió asimismo la de Arenas. Si la de Lorrio se basa, fundamentalmente, en el estudio del armamento, la de los otros autores se adapta a 
investigaciones sobre poblamiento, bien sobre excavación (Arenas 1999) o sobre datos de prospección (Martínez Naranjo 1997). También está presente la revisión cronológica que está llevando a cabo Cerdeño (Cerdeño et al. 1993-1995; Cerdeño y Sagardoy 2007) a partir de la obtención de fechas radiocarbónicas en alguno de los yacimientos por ella investigados. En particular ha de considerarse el hecho de que el estudio de los materiales del nivel III de Herrería ofrece fechas de los siglos VI y V a.C. y la datación de C14 las corrigiera elevándolas a los siglos VIII - VII a.C. La diferencia que nos afecta, respecto a la periodización de Lorrio, es que Cerdeño situaba el comienzo de la fase plena a inicios del s. V a.C., fecha que podría ser revisada a la luz de las fechas radiocarbónicas citadas, y su final en el s. IV a.C., mientras que Lorrio (2005: 259, 275-280) sitúa el inicio a mediados del mismo siglo y el final en el III a.C. Por tanto el Celtibérico Tardío, en el caso de Cerdeño, comenzaría a finales del siglo IV llegando a mediados del II a.C y para Lorrio esta etapa cubriría los siglos III y II a.C. Las dudas mayores proceden del Celtibérico Pleno, cuya adscripción descansa no tanto en fechas radiocarbónicas como en consideraciones tipológicas.

Este es un tema que requeriría el esfuerzo de un consenso. El problema es más profundo que su nomenclatura pues, como es lógico, a cada uno de esos periodos corresponden características y prácticas sociales, religiosas, económicas y políticas que definen un proceso cultural con toda la complejidad de variaciones y ritmos locales o zonales, diferentes pero interrelacionados.

De manera que con los datos que disponemos hasta la fecha, atendiendo al estudio tipológico de materiales y estructuras, la fase mejor representada de nuestra necrópolis es el Celtibérico Pleno, fechada entre finales del siglo V y el IV a.C. en la sistematización de Lorrio (2005), o bien entre comienzos del siglo V y el IV a.C. de seguir a Cerdeño (Cerdeño y Sagardoy 2007), en tanto no se publiquen los resultados de la ultima fase de Herrería. Tras ella, una segunda etapa en la que la necrópolis creció y se reordenó mediante estelas y en la que no aparecen ajuares con armas. Que no se documenten armas propias de fases más avanzadas como los puñales biglobulares, las espadas de tipo La Tène o las de antenas tipo Arcóbriga, además de la información ofrecida por la tipología cerámica, podría llevarnos a comienzos del s. III a.C., en la denominada subfase IIB de Lorrio, o bien situarnos a partir de mediados del s. IV a.C. como hacen la mayoría de los autores. Todo ello en la cronología convencional asignada.

Finalmente adscribiríamos a una última fase de la necrópolis algunos fragmentos cerámicos apare- cidos en C5, en un nivel superficial. Podría fecharse a mediados del siglo III-II a.C. (fase III de Lorrio), o bien a mediados del s. IV-III a.C. según Cerdeño. Se trata de alguna jarra de boca trebolada y fuste de copa alta que -bien formando parte integrante de los ajuares, lo que no creemos, o de algún ritual llevado a cabo sobre las tumbas-, podemos fechar sin dificultad en el siglo III a.C., cuando el ámbito celtibérico meseteño muestra una uniformidad cultural mayor. La última tumba enterrada, con seguridad, C3G13T4, no ofrece datos tipológicos precisos: urna pequeña, ausencia de ajuar y escasos restos óseos. Se depositó cuando la estela estaba ya parcialmente cubierta por sedimentos. Es posible incluso que se enterrara cuando la necrópolis ya no era utilizada.

Estos serían los resultados obtenidos a partir de la cronología relativa.

\subsection{La estratigrafía. Relaciones sincrónicas y diacrónicas}

La excepcional conservación de la necrópolis en el área que no fue afectada por las máquinas permitió registrar una estratigrafía de los enterramientos, tanto en vertical como horizontal, no documentadas en las necrópolis de referencia excavadas en el siglo pasado. Esto tiene consecuencias inmediatas a la hora de determinar una cronología relativa para $\mathrm{El}$ Inchidero siguiendo su desarrollo material y ritual. Al mismo tiempo nos ha permitido establecer una secuencia evolutiva, aunque en algunos casos no podamos superar el nivel meramente descriptivo.

En una primera aproximación, hemos de indicar que existen dos enterramientos en la misma fosa y a igual cota, por tanto sincrónicos; se trata de C3G14T1 y T2 (Figs. 8-9). La tumba C5G10 (Fig.

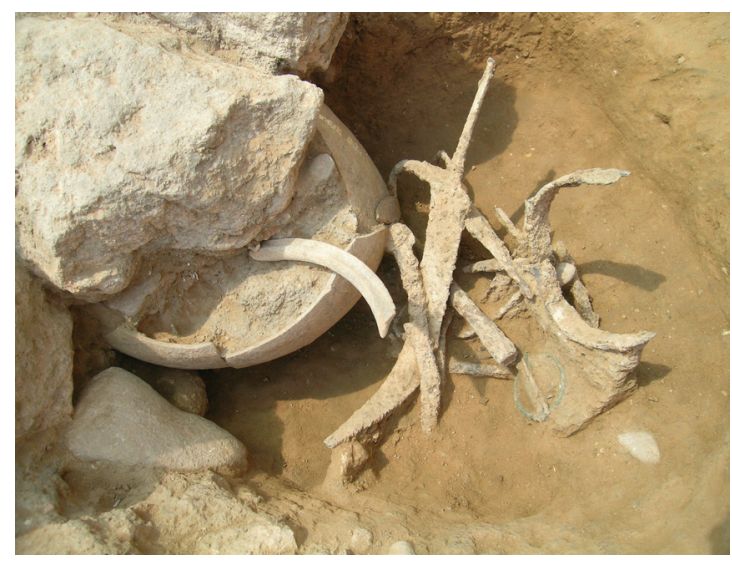

Figura 7.- Tumba C5T9. 


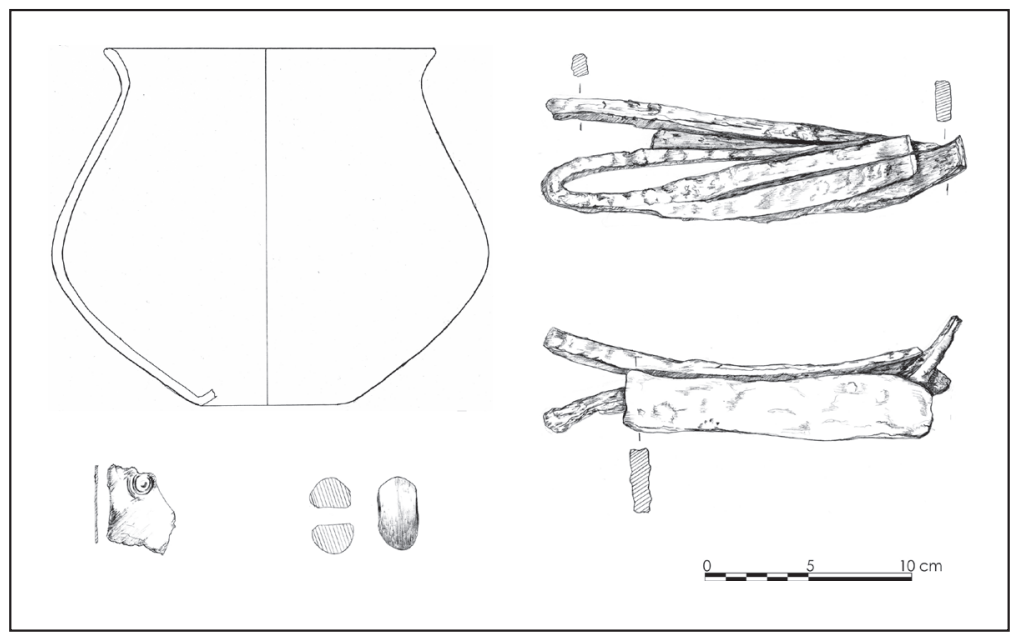

Figura 8.- Urna y ajuar de C3G14T2.

13) es doble pero diacrónica; cuando se produjo el último enterramiento el primero no se había colmatado completamente pues la urna superior quedó encajada en la inferior. Las tumbas C3G7 (T1, T2 y T3) (Fig. 6) y C5G6 (T1 y T2) (Fig. 5) son enterramientos múltiples diacrónicos; el primero de tres y el segundo, probablemente, solo de dos. En ambos casos las urnas precedentes se destruyeron al incorporar la última al enterramiento. Se trata de enterramientos de la última fase documentada de la necrópolis, que denotan mayor simbolismo en la recogida de restos óseos y cierta superficialidad en su modelo de cubrición.

Un segundo nivel de análisis se corresponde con la alineación de tumbas, aunque no podamos extraer ninguna conclusión respecto al orden en que se produjeron los enterramientos. Las alineaciones se dividen en dos áreas: una zona ordenada mediante calles de estelas (C3) y el resto del sector excavado, donde se identificaron alineaciones de tumbas sin ordenación aparente de calles de estelas $(\mathrm{C} 4, \mathrm{C} 5 \mathrm{y}$ C6). En este último caso se consideró la posibilidad de que, por culpa de los trabajos agrícolas o la simple reutilización de las piedras, las estelas hubieran sido arrancadas. Sin embargo la interpretación parece ser más compleja. En el C3 la apariencia de la disposición es ordenada e igualitaria en su distribución espacial y en el tamaño de las estelas (Fig. 6). La estructura de enterramiento de las tumbas C3T12 y C3G13 T1 (Fig. 4 perfil), con una sólida cobertera de piedras, y las tumbas del mismo nivel que fueron expoliadas, definen la primera fase de la necrópolis. De hecho estas estructuras tienen relación, por el modo constructivo, con la tumba C5T9 (Figs. 7-8), cubierta con dos grandes lajas de piedra y protegida en uno de sus lados por una laja dispuesta horizon- talmente. Ambos aspectos nos permiten aventurar, como ya se ha indicado, que la distribución en las fases iniciales de la necrópolis fuese mediante alineaciones de tumbas más o menos regulares, y que en un momento avanzado se reordenara el espacio utilizando estelas. De ser cierta nuestra hipótesis, la necrópolis ocuparía inicialmente una banda que llegaría como máximo hasta la primera alineación de estelas. Bien es cierto que de la banda que resultó destruida recuperamos varias lajas de piedra, algunas de las cuales pudieron funcionar como estelas y otras como lajas protegiendo las urnas. Esta hipótesis explicaría las estelas colocadas a posteriori sobre C3G13T1 y la estela de la tumba 8 de C5, que conllevó la destrucción de la urna. Asimismo hemos de llamar la atención sobre el hecho de que algunas de las estelas que configuran calles no corresponden a ningún enterramiento. La distancia entre hiladas

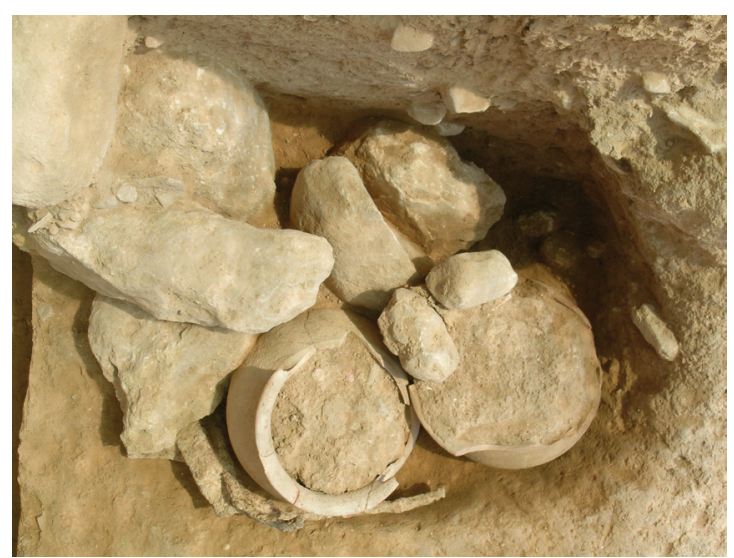

Figura 9.- Tumbas C3G14T1 y T2. Enterramiento de dos urnas en la misma fosa. 


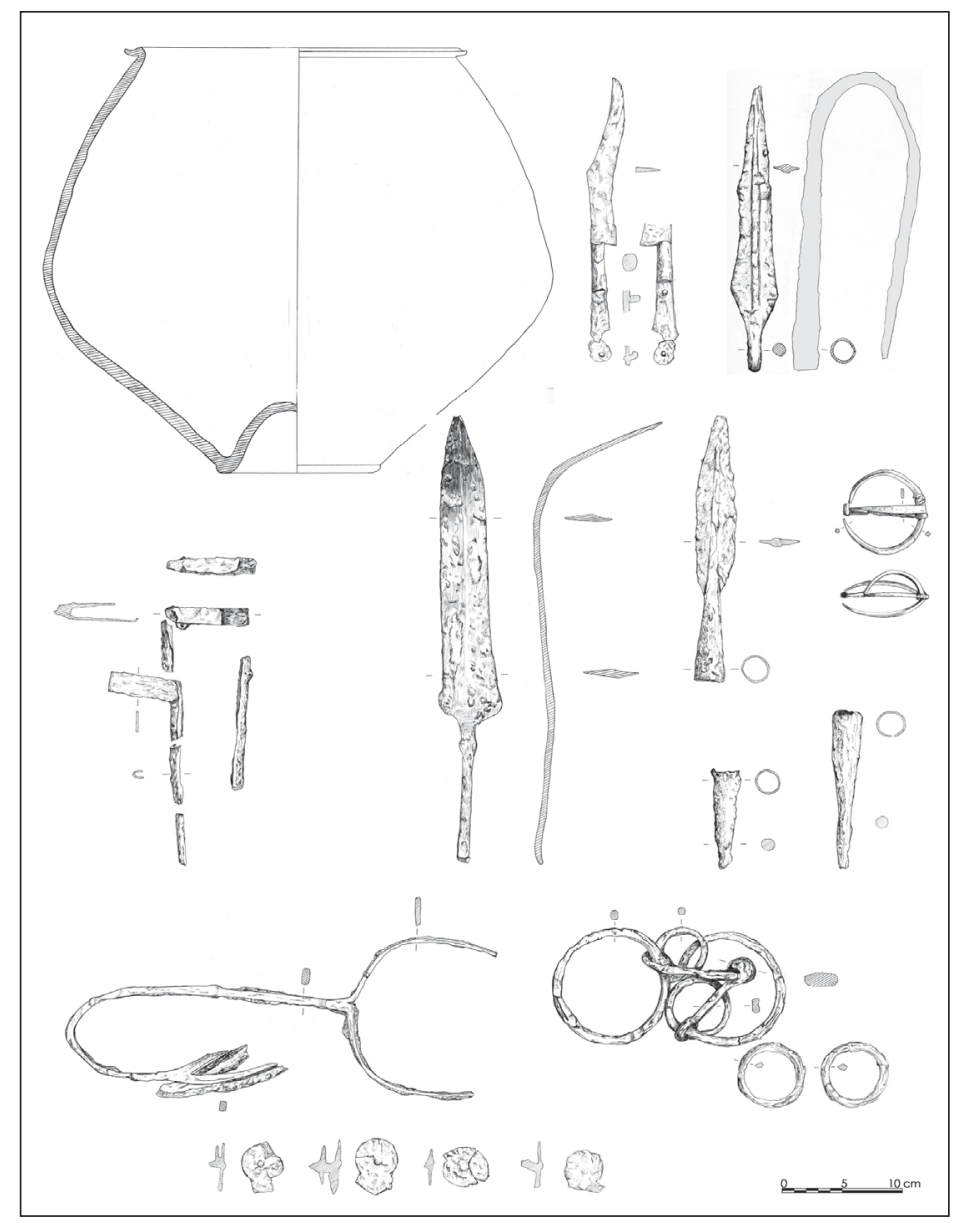

Figura 10.- Urna y ajuar de C5T9; a lo presentado habría de añadir una amalgama de cuentas de vidrio y fragmentos de láminas de bronce completamente doblados e informes.

de tumbas en $\mathrm{C} 5$, con oscilaciones a veces acusadas, es de $80 \mathrm{~cm}$; en $\mathrm{C} 4$ es de $140 \mathrm{~cm}$. Las calles de estelas tienen una anchura media de $50 \mathrm{~cm}$ con oscilaciones leves.

Las alineaciones de tumbas bien definidas, sin estelas, se hallaron en C6, con tumbas muy destruidas, y en C5 (Fig. 3): se trata de las tumbas 5, 10, 9 y la no excavada en el perfil. También en C5 podrían haber seguido una alienación las tumbas 2, 11 y 4, aunque las dos primeras pudieron formar parte de una agrupación de tumbas alrededor de T8 (Arlegui en prensa). Quedarían fuera de esta ordenación la tumba 1 y los enterramientos más superficiales y tardíos (G6T1 y T2). Parece que la disposición de los últimos enterramientos fue mucho más aleatoria; en general responden a criterios de proximidad con enterramientos anteriores.

En C4 las tumbas 1, 2 y 3 formaban una alineación clara; a una distancia regular de esta línea la T5 parece indicar otra nueva de la que se habrían perdido los restantes enterramientos, si es que los hubo. Sin embargo, dado que C4 se halla en la zona donde las máquinas arrasaron las capas superiores no podremos averiguar si algunas de las lajas fueron arrancadas.

Un tercer nivel de definición e interpretación viene dado por el cruce de razones estratigráficas y formales en los modelos constructivos de las tumbas. Obviamente de ello puede extraerse una secuencia de los enterramientos que deja fuera algunas tumbas no relacionables. Facilita también una sucesión correlativa, interna, de la necrópolis a través de relaciones significativas entre tumbas.

Por otro lado, la estratigrafía vertical tiene en C3G13 el grupo de tumbas más significativo que permite, a partir de ella, establecer una secuencia entre el resto de los enterramientos de esta cata (Fig. 4). El primer enterramiento debió ser el C3G13T1, una urna realizada a mano con un elemento de tocado o sujeción como ajuar. Es una tumba de cons- 


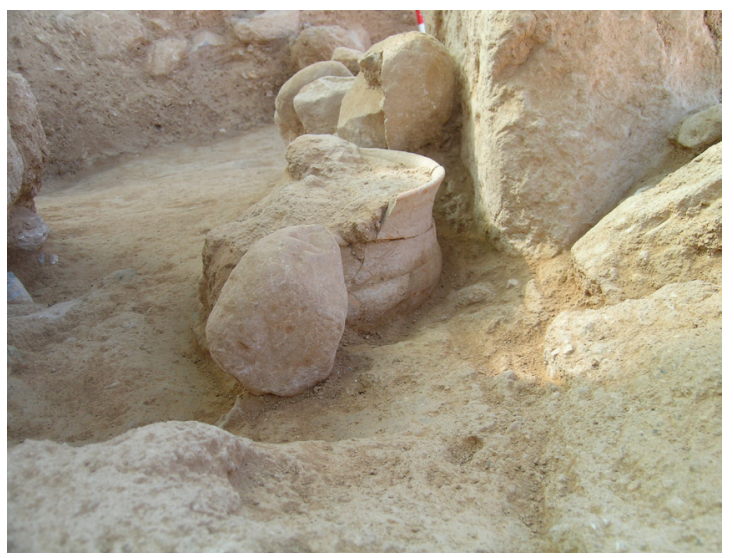

Figura 11.- C3G13T3, tumba correspondiente a la segunda fase.

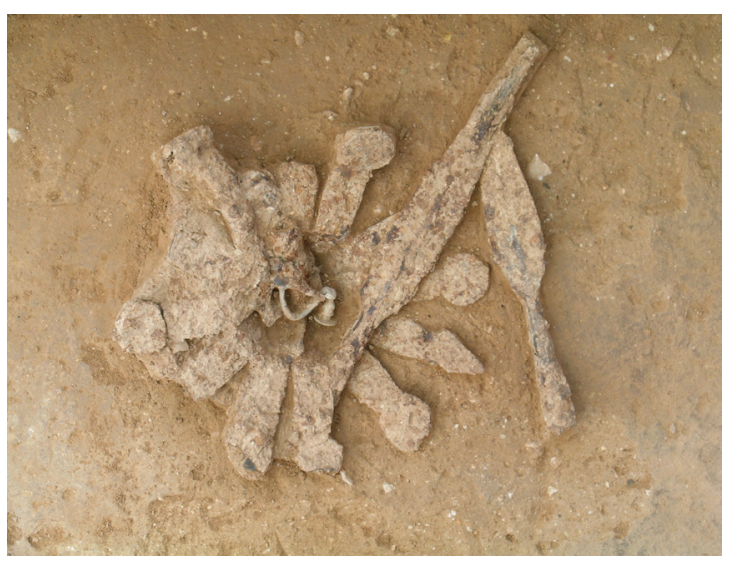

Figura 12.- Ajuar metálico de la C5T8.

trucción compleja en la que se dispuso un "muro" de piedras ante el cual, por su lado oeste, se depositó la urna. Al reordenarse la necrópolis, seguramente al crecer, la estela se colocó ajustándola con un importante número de piedras a su alrededor. Al mismo tiempo se depositaron los enterramientos C3G13T2 y T3 (Fig. 11) en los ángulos SE y NE respectivamente, sin ajuar externo y con idéntica forma cerámica, aunque no podamos precisar el tiempo transcurrido entre ambos. Es significativo que ninguna de estas dos tumbas ocupe el espacio central. La última tumba se situó en la cara Oeste de la estela, cuando ya existía una capa de sedimentación importante sobre las sepulturas. Lamentablemente la pérdida o alteración de la cubierta de la tumba, la forma cerámica -un cuenco de pequeñas proporciones- y los escasos restos óseos que contenía no permiten una aproximación cronológica. Pero si podemos añadir que, dentro del sector excavado, se trata del último enterramiento, e incluso pudo tener lugar cuando la necrópolis ya había sido abandonada.
Por tanto esta agrupación de tumbas reflejaría las tres fases que asignamos a la necrópolis, sin que podamos saber con exactitud si entre la primera y la segunda existió ruptura o sucesión.

La tumba 12 de esta $\mathrm{C} 3$ se construyó después de la tumba C3 G13 T1. Los ajuares son idénticos -elemento de tocado o soporte- y la urna de la T12 está hecha a torno. Ambas tumbas son adyacentes -separadas con unas pocas piedras y colocadas en la cara oeste de su estructura- y en ambas el ajuar metálico se colocó sobre la urna. Una gran laja de unos $10 \mathrm{~cm}$ de grosor y $30 \mathrm{~cm}$ de largo cubría la urna 12 , pero no localizamos la estela que debía corresponderle. Cabe la posibilidad de que la máquina la arrancara. No en vano el lado Oeste de la cata 3 fue realizado por la máquina que cortó la necrópolis en este punto. Quedaron en el perfil los enterramientos T12 y G13T1, dando una perspectiva inusual del conjunto.

La tumba doble, C3G14 (Figs. 8-9), deberíamos situarla tras las dos anteriores (C3G13 T1 y C3 T12) y antes de las tumbas C3G13 T2 y T3 (Fig. 11). No tuvo estela. De hecho en el perfil puede verse una tumba expoliada bajo la tumba C3G14, enterramiento que correspondería al horizonte de las tumbas de la primera fase de la necrópolis. Además de la evidencia estratigráfica y del modo de construir mediante un "murete" irregular de piedras, sus ajuares también están formados por un elemento de tocado de hierro. La tipología de las urnas parece intermedia entre la T12 y las urnas G13T2 y T3. Lo incluimos en la primera fase por las características formales de la estructura y el tipo de ajuar.

Las urnas de las tumbas $\mathrm{C} 3 \mathrm{G} 7 \mathrm{~T} 1$ y $\mathrm{T} 2$ podrían ser comparables a las del enterramiento doble anterior. Sin embargo los enterramientos del G7 son superficiales, no en fosa, y se corresponden con tumbas sin ajuar externo y pobre ajuar interno. Se

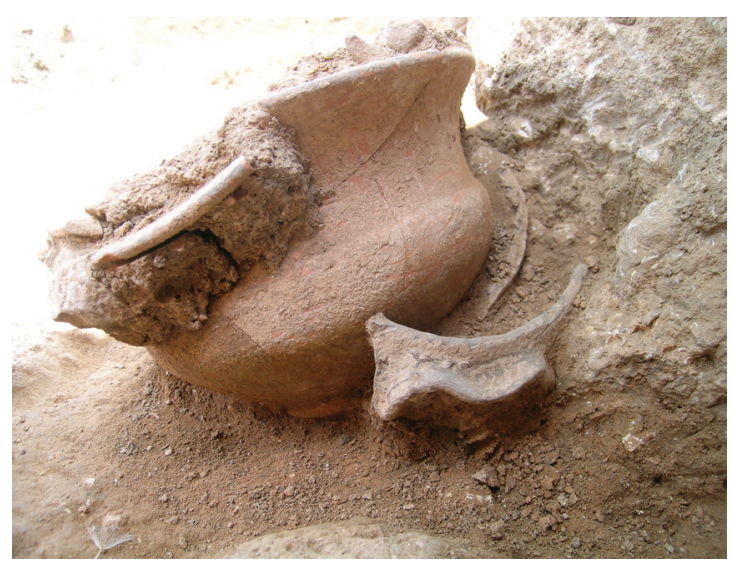

Figura 13.- Tumba doble C5G10T1 y T2; esta última perteneciente a la última fase de uso de la necrópolis. 
antepusieron a su estela, sin que haya enterramiento bajo ellos. Su cubierta debió de ser con piedra y tierra sin fosa diferenciada.

El C5 es mucho más complejo de interpretar. En él hallamos la tumba C5T8 (Fig. 12). El ajuar se dispuso de forma cuidadosa y ceremonial: el umbo radiado con el tachón hacia abajo, y sobre él la manilla del escudo, los elementos para colgar el telamón y un cuchillo afalcatado. La punta de lanza mayor se colocó sobre él casi en diagonal y su extremo inferior se introdujo bajo uno de los radios, que fue curvado. La punta de lanza menor se dispuso al Norte del escudo y en paralelo a él. La fíbula fue la última pieza colocada. La urna fue parcialmente destruida al hacer la fosa para la estela, que debió colocarse con posterioridad al enterramiento. Se trata de un cuenco alto, a mano y de gran diámetro. En esta misma fase, atendiendo a la evidencia estratigráfica y al modo de construir la tumba, deberíamos situar la sepultura C5T9 (Figs. 7-10) -con restos de tres individuos en una urna inusualmente grande cuyo ajuar es el más completo- y la C6T2, también una tumba "rica".

El enterramiento C5T4 sigue la alineación de C5T8 y se depositó en un hoyo protegido con una laja lateral. La punta de lanza, doblada, se colocó bajo la urna. Esta tiene forma globular y está decorada con líneas paralelas en negro que hace sospechar una cronología no anterior al siglo IV o inicios del V a.C.

Atendiendo a las características del ajuar, con umbo radiado y punta de lanza, la tumba C5T11 se puede relacionar con C5T8 y C6T2. Se acompaña de una laja dispuesta horizontalmente, como también ocurre en C5T5 y C5G10T1. Sin embargo, estratigráficamente está en un nivel superior a aquellas; la urna, de entre las que tienen ajuares con armas, es de menor tamaño, lo que implica una fase de cambio. La forma de C5T11 es la misma que la de las urnas de la tumba doble C3G14 (T1 y T2), lo cual nos permite relacionar ambos sectores de la necrópolis con vistas a su seriación. El ajuar, con umbo de escudo, se puede relacionar con la C5T8, como ya hemos indicado, y la C6T2.

Las tumbas C5G6T1 y T2 son las últimas que se realizaron en C5. Pertenecen a la Fase III de la necrópolis. A ellas hemos de sumar las dos urnas aparecidas (muy destruidas) entre el enterramiento C5T8 y la estructura de la T4, en un nivel superior. Corresponden a otro tipo de enterramiento: urnas más pequeñas sin ajuar, restos óseos escasos y muy fragmentados, y una cubierta sencilla de piedra y tierra.

Queda fuera la tumba C5T2. Apareció embutida entre la plataforma de piedras que señala y protege una agrupación alrededor de la tumba C5T8. Es un cuenco a mano que seguramente se depositó al mismo tiempo. Algo parecido vemos en la Tumba 1. Conservaba parcialmente la cubierta que debió darle el aspecto de túmulo oval. La urna estaba en la periferia del túmulo. Se trata de un enterramiento antiguo, sin ajuar, cuya cronología relativa es difícil de establecer así como su relación con las restantes urnas. En cuanto a los enterramientos de C6, dado su estado de conservación, las conclusiones son bastante más pobres. Sólo podemos establecer una relación entre el enterramiento C6T2 y las tumbas de C5T8 y C5T9, atendiendo a la similitud de sus ajuares.

De manera que, de acuerdo con la tipología de los enterramientos y la evidencia estratigráfica, podemos establecer la siguiente secuencia. A la Fase I corresponderían los enterramientos C3G13T1, C3T12C3, G14T1 y T2, siguiendo el orden en que fueron depositados. En el mismo nivel estratigráfico junto a las tumbas C3T12 y C3G13T1 e igual modo de construir las tumbas hemos de encuadrar los enterramientos que correspondieron en su momento a las estelas 10 y 11 y que sospechamos fueron extraídos manualmente a la vez que las máquinas abrían el perfil. Respecto al C4 no podemos aventurar ningún aspecto mientras no se excaven los bloques de ajuar ${ }^{2}$. Una dificultad añadida descansa en el hecho de que la parte superior del nivel arqueológico que afectaba a la cobertera de las tumbas y su señalización fue arrancado por las máquinas. No obstante podemos señalar, por las características de los ajuares, que deben relacionarse cronológicamente con las tumbas C3T12 y C3 G13 T1, C5 T8, C5 T9 y C6 T2. Por último se incluirían en esta primera fase la tumba C5T11 -aunque estaba en una cota más alta que C5T8 y, tal vez al final de la fase, la C5T4, sin excluir su adscripción a la siguiente. Se trata de enterramientos dispuestos en línea y constituidos por pequeñas fosas donde se depositaba la urna, protegida lateralmente con una laja y cubierta con piedra y tierra a excepción de C5T9 (Figs. 7-8), que debió tener aspecto de tumba plana. La cremación debió llevarse a cabo a una temperatura inferior de la de las fases posteriores, como se advierte en la coloración y escasa fragmentación de los huesos. La recogida fue exhaustiva y los huesos colmatan las urnas. Sobre éstos suele disponerse una capa de cantos rodados. Probablemente tuvieron una señalización perecedera al exterior. Los ajuares metálicos de armas o peinetas se situaban fuera, incluso la fíbula en los más ricos. En el interior, fusayolas, a veces la fíbula, placas de bronce, cuentas de collar, algunas de ellas de ámbar...

La segunda fase de la necrópolis implica un crecimiento y una reordenación del espacio mediante estelas. Salvo un caso, todas son de similar tamaño. 
A esta fase corresponderían las tumbas C3G13T2 y T3, C3 G7 T1 y T2. Las urnas son más pequeñas y los tipos estandarizados. No parece que tuvieran un uso doméstico previo, algo que sí constatamos en la primera fase. La cremación se realiza a mayores temperaturas, los restos óseos aparecen muy fragmentados y su recogida es selectiva. Desaparecen las armas y los tocados de hierro. Los ajuares, siempre depositados en el interior de las urnas, lo forman espirales de bronce, cuentas de collar también de bronce y fusayolas.

Por último, a una tercera fase corresponderían las tumbas superficiales C5G6T1 y T2, y C3G13T4. Su cubrición es sencilla -tierra y algunas piedras- las urnas muy pequeñas, y la recogida de huesos prácticamente simbólica. Incluimos también en esta fase los fragmentos de copas y jarras trilobuladas. En el estudio estratigráfico quedan fuera, como ya se ha indicado, las tumbas C5T1, C5T2 y C5G10T2, aunque esta última apareciera encajada sobre otra anterior.

\section{3.- Seriación tipológica de los materiales}

En la cronología de las piezas que abordaremos a continuación, dejaremos de lado los materiales descontextualizados o aquéllos que fueron recogidos por un vecino de Aguilar de Montuenga y entregados al Servicio Territorial de Cultura de Soria. Entre ellos la orejeta de una urna cuya tipología ha sido bien fechada alrededor del siglo VI a.C. en El Turmielo (Arenas y Martínez Naranjo 1993-1995), aunque su presencia mayoritaria corresponda al siglo V a.C. Tradicionalmente considerada una pieza de importación, aparece en sepulturas "ricas" como en las necrópolis de Aguilar de Anguita, Prados Redondos, Sigüenza o Luzaga. La pieza encaja bastante bien para el arranque de la necrópolis, aunque no podamos adscribirla a ninguna tumba. Se entregó también un soliferreumm que probablemente corresponda al tipo F de Quesada (1993: Fig.2, lam. IIB), aunque pudo haber tenido un engrosamiento por enmangue en cuyo caso correspondería al tipo A. Este autor considera que su utilización en la Meseta, ya documentada en Aguilar de Anguita, pudo mantenerse o "reavivarse" en el siglo IV a.C. perdurando hasta el último tercio del siglo I a.C., en el ámbito ibérico turdetano y meseteño. En La Olmeda de Jadraque se fechan entre los siglos VI y III a.C. (García Huerta 1980: 19), en Aguilar de Anguita entre los siglos V y IV a.C. (Quesada 1993: 176), en la tumba 407 de Carratiermes alrededor de la segunda mitad del siglo IV a.C. (Argente et al. 2000: 69) y en la necrópolis de El Atance entre los siglos VI-II a.C. (de Paz 1980: 53 y Quesada 1993: apéndice).
En otros casos hemos omitido aquellas piezas cuyos modelos perduran en el tiempo hasta abarcar todo el período celtibérico; por ejemplo algunos cuchillos o pinzas que, ya desde la fase IIA de Lorrio (2005), alcanzan el siglo I a.C., los adornos en espirales o las fusayolas que, de aceptar su presencia en tumbas femeninas de mediados del siglo $\mathrm{V}$ a.C. (Argente et al. 2000: 210), también aparecen en tumbas de los periodos IIA y IIB de Lorrio (2005). Idéntica asignación tienen las bolas de cerámica, si bien Requejo (1978: 59-60) señala que éstas no son anteriores al IV a.C., o bien las cuentas de collar, generalmente datadas en el Celtibérico Pleno y que ahora, una vez revisadas, sobre todo las de ámbar, nos remiten a un momento anterior (Cerdeño et al. e.p.). Por último, incluimos aquí los bocados de caballo; contamos con los importantes estudios de Quesada (2005) y Baquedano (1990), pero todavía tenemos notables dificultades en su adscripción morfológica y cronológica.

En cualquier caso, algunas de las piezas citadas servirían para confirmar las fechas del Celtibérico Pleno (inicios del V a.C.) que asignamos a la fase más representativa de la necrópolis en la zona excavada. A ello debe sumarse que los ajuares más antiguos contienen la panoplia completa, lo que resulta un rasgo del inicio de esta fase. Asimismo, la incorporación de la espada (tipos Aguilar de Anguita y de frontón) a los ajuares se produce por primera vez en algunas necrópolis del Alto Tajo-Alto Jalón (Aguilar de Anguita, Alpanseque, Sigüenza...) en la subfase IIAI de Lorrio (2005), lo que correspondería a la casi totalidad de las espadas recuperadas, muchas de ellas híbridas. Lorrio sitúa este acontecimiento en el siglo V. a.C., rebajando la fecha del siglo VI que diera Schüle (1969), lo que también valdría para los soliferrea, escudos de grandes tachones, discos coraza y cascos.

Otro dato que nos ayuda a situar la necrópolis en el tiempo es que, si bien ésta pervive hasta un momento en el que los enterramientos carecen de ajuares significativos, no se han documentado espadas de tipo Arcóbriga ni de La Tène, ni tampoco puñales biglobulares. La costumbre de depositar armas se produce con anterioridad a este hecho, lo que abre un interesante campo de interpretación en el ámbito de lo social y lo político.

A continuación abordaremos la secuencia evolutiva de la necrópolis, tomando como referencia las fases establecidas y, cuando proceda, los materiales más significativos recuperados en las tumbas.

Fase I: Corresponde a las tumbas C3T12 y C3G13T1. Como ajuar externo se acompañan de los elementos de tocado (Aguilera 1916: 61-62) o soportes (Cerdeño y Sagardoy 2007: 137-139), 
incluidos por Lorrio (2005: tabla1) en su fase IIB; en Aragoncillo se fechan en el Celtibérico Antiguo (Arenas 1990) y en Herrería en su fase III. Un tipo cerámico similar a la urna a torno de la C3T12 se fecha en Carratiermes en el siglo V a.C., asociada a una fusayola, un cuchillo, una punta de lanza, restos de contera y un broche de tres garfios (Argente et al. 2000: 169-171). La urna de C3G13T1, hecha a mano, es menos elocuente desde el punto de vista tipológico y pervive, en ambientes domésticos, a lo largo de todo el periodo celtibérico pleno y aún tardío.

Respecto a los ajuares con armas hemos de señalar el alto número de espadas recuperadas: a las dos halladas en el proceso de excavación (sin saber si los ajuares de C4 contienen alguna), hemos de sumar las entregadas al Servicio Territorial de Cultura. El número es proporcionalmente alto, máxime considerando que todas proceden de la banda que fue arrasada por las máquinas. Curiosamente estas espadas y puntas de lanza estaban sistemáticamente dobladas, de una forma que nosotros no hemos documentado en la excavación.

Hemos señalado como uno de los enterramientos de esta fase, el C5T8 (Fig. 12), carecía de espada a pesar de su abundante y significativo ajuar. El umbo de escudo, radiado y rematado con círculos (aunque este fuera después reparado en puntas), con un tachón de cubo truncado, corresponde a un tipo muy representado en la Meseta Oriental, fechándose desde mediados del siglo V a.C. en Alpanseque y el siglo IV a.C. en Aguilar de Anguita. Dado el diámetro $(34 \mathrm{~cm})$, podemos considerarlo como "gran escudo". Es el tipo IIA de Quesada (1997: 511, Fig. 296). Nuestro ejemplar apareció acompañado de una manilla simple sin aletas que conserva clavos del remache, tipo IB de Quesada o I de Cuadrado (1987 y 1989). El primer autor la fecha en el siglo $\mathrm{V}$ a.C. y el segundo en el IV a.C. Las dos puntas de lanza pueden corresponder a los tipos VB la primera, y VC o IIC de Quesada la segunda. Los tipos VB y VC suelen fecharse entre los siglos IVII a.C., y el IIC entre los siglos IV-III a.C. (Quesada 1997:363). Sin embargo el tamaño de ambas, la escasa diferencia entre las dos y el característico nervio central nos permiten pensar en un tipo ligeramente más antiguo: parecidas a las nuestras son las recuperadas en la tumba 29 de Sigüenza, con un puñal de frontón, y la tumba 3 de Atienza, ambas fechadas en la fase IIA de Lorrio (2005). La base de la hoja, que es decisiva para Quesada a la hora de determinar el tipo, nos resulta indeterminable. El cuchillo afalcatado se fecha en el siglo V a.C. La fíbula es, probablemente, del tipo $7 \mathrm{C}$ de Argente, datada desde la segunda mitad del siglo VI a.C. o primera mitad del V a.C. hasta el siglo IV a.C.
(Argente 1994), aunque podría haber perdido uno de sus pies elevados y relacionarse entonces con el tipo 8.1.1. (Argente 1994: 84-85), de manera que se dataría entre finales del siglo $\mathrm{V}$ a.C. y mediados del III a.C. Hemos de indicar sin embargo que la fíbula de bronce tiene la aguja de hierro, probablemente resultado de una reparación, y que en su pie vuelto conserva una pequeña cinta que pudiera haber servido para añadir una cadenita. Su urna, a mano, comparable a la forma $\mathrm{V}$ de Carratiermes, pervive a lo largo de toda la Edad del Hierro (Argente et al. 2000: 137-139, Fig. 59). En Luzaga aparece decorada con estampaciones y líneas incisas y se fecha entre los siglos IV-III a.C. (Díaz 1976: Fig. 20). Otros ajuares con umbo radiado rematado en círculos son los de las tumbas C5T9, C6T2 y C5T11.

La tumba C5T4 contenía una urna hecha a torno cuya forma, similar en Carratiermes (forma I.3) se fecha entre los siglos V-III a.C. (Argente et al. 2000: 169-170, Fig. 63), fechas en las que se incluyen sin demasiada precisión las de Luzaga, como la urna 40/27/L281 (Díaz 1976) o la forma 8 de La Riba de Saelices (Cuadrado 1968, Fig. 13). La pieza de Aguilar de Montuenga nos remite en cuanto a su forma, muy globular, a tipos antiguos; sin embargo conserva finas líneas horizontales pintadas en negro. La fíbula anular de hierro hallada en su interior, en muy mal estado de conservación, corresponde al tipo 6B o 6C de Argente. El primero se fecha en Carratiermes entre los siglos V-IV a.C. y el segundo entre el IV-III a.C. (Argente et al. 2000: 95). A este último tipo corresponden también las de Monteagudo de las Vicarías y del Vado de la Lámpara de Montuenga de Soria. Recordemos que en la actualidad las fíbulas de hierro se consideran antiguas. La punta de lanza remite sin embargo a modelos antiguos, tal vez el tipo IIA1 de Quesada. Todo ello nos llevaría a atribuir a este enterramiento una fecha en ningún caso anterior a mediados del siglo IV a.C.

Similares problemas de cronología ofrece el ajuar de la tumba C5T9 (Figs. 7-10), uno de los más numerosos y variados: el tipo de urna, inusualmente grande, con un labio zoomorfo que nos remite seguramente a una pieza importada aunque su factura resulta tosca, se fecha en el Celtibérico Antiguo en el Palomar I (Arenas 1999, Fig.19.1), en el Celtibérico Pleno en el Palomar II y en la fase III de La Torre de Codes (Arenas 1999: Fig. 22.4 y 56 respectivamente). Equivale a la forma 14 de García Huerta (1990) y al tipo V.2 de Carratiermes. (Argente et al. 2000: 175- 176). El cuchillo de empuñadura maciza, considerado por ello un modelo antiguo, acodado, es comparable al de la tumba 67 de La Mercadera o al de la tumba A de Aguilar de Anguita (Schüle 1969), donde apareció asociada con una urna de orejetas, 
una espada de frontón y un umbo de escudo similar a los de las tumbas C5T8 y C5T11 de Aguilar de Montuenga. La espada sin embargo es de un tipo indeterminable, fundamentalmente porque no conserva la empuñadura. El largo de la hoja permitiría considerarla tipo Aguilar de Anguita ya que su vástago no se corresponde a los de frontón. Como hemos indicado el soporte o peineta tiene una amplia cronología que llega hasta el momento en que los ajuares se empobrecen. La punta de lanza parece responder al modelo antiguo IIA1 de Quesada y similar por tanto a la de la tumba C5T4 antes sintetizada. La fíbula anular de bronce presenta dificultades para determinar si corresponde al modelo $6 \mathrm{~B}$ o 6C de Argente (1994: 68 y 68-69 respectivamente), el primero fechado desde el siglo $\mathrm{V}$ a.C. a la segunda mitad del III a.C. y el segundo entre los siglos IV-II a.C. Ambos son típicos de la Meseta Oriental. En El Vado de la Lámpara el tipo 6C de Argente o 2A de Cuadrado (1968) se fecha en el siglo IV a.C.

Por último, el estudio del ajuar de la tumba C6T2 se basa solo en las piezas metálicas; la urna, muy fragmentada, no ofrece ningún dato cronológico. La fíbula de pie alzado zoomorfo, de gran calidad, del tipo 8A3 de Argente (1994: 84 y 93), de La Tène inicial, o tipo 2a de Cabré y Morán (1978: 20), se fecha entre los siglos V-IV a.C. Argente indica que ninguno de los casos que sirvieron para definir el modelo procedían de conjuntos cerrados. La más parecida a la nuestra se localizó en Alpanseque, en donde Cabré y Morán (1975: Fig. 3,1) la fechan con seguridad en el primer tercio del siglo IV a.C. y en ningún caso más allá del 350 a.C.

La espada es del modelo Aguilar de Anguita, tipo III de Quesada. Tiene la hoja pistiliforme y la empuñadura aplanada (que caracteriza los tipos V y VI de Quesada), guarda recta con escotadura rectangular hacia la hoja y parece tener muescas laterales -características en el tipo V-además de antenas casi esféricas. Este autor las fecha desde principios del siglo V hasta la mitad del siglo IV a.C. Podemos compararla, especialmente, con la aparecida en la tumba 27 calle II de Alpanseque (Schüle 1969), que se incluye entre las más antiguas de la fase IIA1 de Lorrio (2005: 159). Además de estas piezas, se incluye la vaina de la espada que corresponde claramente al tipo II de Quesada o "Aguilar de Anguita", un bocado de filete, dos puntas de lanza y unas pinzas de bronce.

Sin ajuar pero correspondiente a esta fase consideramos las urnas C5G10T1 (sobre la que apoyaba otra urna que quedó encajada, Fig. 13), C5T2 y C5T5. Ésta última urna, a torno, de pequeño tamaño (su altura es de $9,9 \mathrm{~cm}$.), tiene una forma idéntica a la de la tumba VI de El Altillo de Aguilar de Anguita (Argente 1977: 121 y Fig.11.1). Cuadrado la sitúa entre las formas 1d y 11a de La Riba de Saelices (1968: 14 y Fig.11). Asimismo mantiene claras concomitancias con las documentadas en Monteagudo de las Vicarías (Taracena 1932: 34, lám. XXIV A.1.2., 1.4 y 3.7). Es una forma frecuente en El Atance (de Paz 1980: fig. 6.1 y 7.2) y Prados Redondos (Fernández Galiano et al. 1982, fig. 12.1, 14.1 y 3). En Carratiermes es la forma IV.1.4, que se fecha entre la segunda mitad del siglo V a.C. hasta la primera mitad del tercero aunque, de seguir a sus investigadores, también podría cubrir todo el siglo III a.C. (Argente et al. 2000: 174). La urna C5T2, embutida en el empedrado, es un cuenco, casi plato, hecho a mano y decorado con dos mamelones verticales para el que no hemos encontrado ejemplos comparables en otras necrópolis. Procedentes de poblados, el más parecido al nuestro es el recuperado en el sector II de La Torre de Codes (Arenas 1999: fig. 62, 1 y 2). La urna C5G10T1, sobre la que apoyaba encajada otra urna, tiene forma de cuenco con dos asideros contrapuestos, cerca del borde, de cinta ondulada dispuesta horizontalmente. No conocemos ningún paralelo formal.

La tumba doble C3G14T1 y T2 (Figs. 9-10), estratigráficamente en un nivel superior a las restantes de la fase I, la incluimos aquí por las características constructivas de la tumba, porque no tenía estela y porque cada una de las urnas que contenía llevaba como ajuar externo uno de los elementos que venimos designando por comodidad de tocado. Las urnas sin embargo son iguales a las de la tumba C3G7T1 y T2 que incluimos en la fase II. Es un tipo similar a la forma III,3 de Carratiermes, en donde de nueve conjuntos con esta forma cerámica solo uno presentaba armas. Comenzó a usarse en el siglo IV a.C. y se mantuvo a lo largo del III a.C. (Argente et al. 2000: 172- 173, Fig. 63). En Luzaga es la forma III.2.a (Díaz 1976: 420, Fig. 7) y en La Yunta es la forma 6 (García Huerta 1990). Igualmente encontramos una coincidencia formal con la urna de la tumba 14 de La Cerrada de los Santos II, fechada en el período Celtibérico Pleno (Arenas 1999, Fig. 38). Almagro y Lorrio (1987: 272) recogen una forma similar a ésta en Molina de Aragón, forma 2a, que fechan a partir del siglo IV a.C., perdurando hasta un momento impreciso de la primera mitad del siglo I a.C. En el límite superior coinciden con el asignado por Argente (1977: 138) para el mismo tipo en la necrópolis de Aguilar de Anguita.

Fase II: La necrópolis se organiza en calles de estelas, se advierte una cierta estandarización de las urnas, los ajuares externos formados por armas desaparecen y los ajuares internos resultan mucho más modestos: algún fragmento de espiral en bronce o fusayolas. Este último hecho debe relacionarse 
con la fase en la que desaparecen los ajuares de las tumbas y que se fecha tradicionalmente entre mediados del siglo IV y principios del siglo III a.C. Entre los enterramientos que asignamos a esta fase se encuentran C3G13T2 y T3. Se depositaron alrededor de la estela 13 en su cara este, en dos ángulos diferentes y sobre la tumba C3G13T1, rodeadas de piedras en su base y cubiertas con tierra y piedras. La T3 tenía una base de barro endurecido y en uno de los laterales conservaba adobes dispuestos como una especie de recrecido. La cerámica es depurada y muy frecuente en contextos domésticos donde se mantendrá, con variantes, durante varios siglos. No aparece en la tabla que elaborara García Huerta (1990). En Luzaga se incluye en la forma IV.4b (Díaz 1976, Fig. 9,9). Ejemplos evolucionados del Celtibérico Tardío se encuentran en El Palomar III, con decoración pintada (Arenas 1999: Fig. 131 inf.). Aunque el tipo de Aguilar de Montuenga parece más antiguo que los citados, debemos situarlo entre los más modernos de la necrópolis por razones fundamentalmente estratigráficas.

En el enterramiento doble C5G10 las urnas aparecían depositadas una sobre otra; la superior, C5 G10T2, podría incluirse en esta fase teniendo en cuenta su semejanza con la hallada en la tumba 7 de Carratiermes, asociada a una espada de antenas y un bocado de caballo y fechada en el siglo IV a.C. (Argente et al. 2000: 172-173, Fig. 69). Las necrópolis de La Riba de Saelices (forma I), La Yunta (forma 7) o Luzaga (forma III.2.a) (Díaz 1976: Fig.7,4) confirman la pervivencia del tipo hasta el siglo III a.C.

Fase III: Corresponde a enterramientos superficiales, con cubierta de tierra y piedras y escaso ajuar: unas pocas cuentas de collar, probablemente de hueso, alguna aguja de bronce (C5G6), vasos cerámicos de pequeño tamaño y muy pocos restos óseos.La tumba C3G13T4 es, probablemente, una de las últimas urnas depositadas como ya comentamos antes. Se enterró cuando el nivel de sedimentación cubría casi la mitad de la estela. Se encuentra en la cara oeste de la estela 13, sobre dos niveles de enterramiento precedentes (C3G13T1 y C3G13T4). Sin ajuar asociado, la urna es un cuenco muy pequeño que resulta frecuente en espacios domésticos, no así en contextos funerarios como los de Luzaga, La Riba de Saelices o Molina de Aragón. En Carratiermes se asocia a la forma VIII.4 y se fecha entre mediados del siglo IV y el III a.C. (Argente et al. 2000: 178-179, fig.63). En la necrópolis de La Yunta piezas similares se utilizaron como tapadera (García Huerta y Antona 1992). Los restos óseos recuperados son insignificantes. Por último, adscribimos a esta fase fragmentos cerámicos o urnas completamente disgregadas que aparecieron en la capa más superficial de la necrópolis, alguna jarra trilobulada y fragmentos de copas con pie medianamente desarrollado.

\section{Las dataciones radiocarbónicas}

Las muestras seleccionadas corresponden a ocho urnas de las que se extrajeron los restos óseos en medida suficiente para su análisis. Una de ellas no pudo ser analizada por lo que el conjunto de muestras que ahora analizamos se refiere a siete muestras de las siguientes tumbas: C5T4, C5T5, C5T8, C5T9, C5G10T2, C3G13T3 у C3G14T2. La elección se hizo atendiendo, en primer lugar, a la seguridad de que no estuvieran contaminadas y que fueran representativas del contexto arqueológico que pretendíamos fechar según las diferencias y fases que habíamos observado estratigráfica y cronotipológicamente sin olvidar que, respecto a los requerimientos de sincronía (Bowman 1990) y asociación (Waterbolk 1971 y 1983), la incineración es posterior a la elaboración de los materiales arqueológicos que la acompañan pero sincrónica de la construcción de la tumba.

Partíamos obviamente de la interpretación estratigráfica de un yacimiento complejo y del estudio de materiales por analogías morfológicas y series evolutivas, según directrices arqueológicas, resultando de ello una reconstrucción de la evolución de la necrópolis en términos de cronología relativa. Con la serie relativamente amplia de muestras analizadas pretendíamos minimizar una posible falta de exacti$t u d$, referido este como la mayor o menor proximidad a la fecha real de la muestra analizada, y de precisión, entendida como la amplitud del intervalo temporal dentro del cual se encuentra la fecha real para una probabilidad determinada, habitualmente del $68 \%$ (Gillespie 1984). Hemos intentado aumentar la precisión enviando varias muestras de cada fase, incluyendo algunas que presentaban incertidumbre por poseer rasgos de dos de ellas. Consideramos que la verdadera importancia de las dataciones radiocarbónicas se halla en permitir corroborar o precisar las secuencias dentro del yacimiento y entre yacimientos.

Las muestras fueron enviadas a Beta Analytic Inc. y analizadas mediante el procedimiento de datación radiocarbónica AMS. Cuatro de las muestras fueron realizadas sobre colágeno extraído del hueso (290576, 290577, 290581 y 290583); las tres restantes sobre carbonato extraído de huesos que habían sido sometidos en la cremación, a temperaturas superiores a $600^{\circ} \mathrm{C}(290579,290580$ y 290580$)$. Este carbonato estructural, de difícil contaminación, ofrece ya en la actualidad una datación AMS fiable. Todas 
fueron sometidas a pretratamiento lo que evita fechas de edad subjetiva. A excepción de la correspondiente a C3T12 que no pudo ser analizada, las restantes siete muestras depararon dataciones radiocarbónicas convencionales que fueron sometidas por el propio laboratorio a calibración dendocronológica según el protocolo INTCAL 04 Radiocarbon Age Calibration (Stuiver et al. 1998). Con posterioridad aplicamos el programa Calib Radiocarbon Calibration que utiliza la nueva curva de calibración INTCAL 09 (Reimer et alii 2009), accesible en la página web de la Universidad de Washington, Quaternary Isotope Lab, con el objetivo de obtener una combinación de fechas y la estructura percentílica de las series de fechas. En ambas la vida media es el valor establecido por Willard Libby de 5568 para el cálculo de edad. Aunque CALIB deparó mayor número de rangos calibrados todos excepto uno coincidían en sus extremos, con ligera variación, con los ofrecidos por BETA.
En la tabla 1 hemos incluido los resultados de calibración de los dos programas (INTCAL 04 e INTCAL 09) buscando una mayor precisión e incluso pretendiendo que los datos que habíamos percibido como anomalía (según los parámetros estratigráficos y cronotipológicos) de los resultados de Beta Analytic fueran aún más explícitos. Esta tabla parte de los resultados de Beta indicando las fechas C-14 convencionales siempre con la incertidumbre como desviación típica de su distribución de probabilidad e incluye los datos básicos de medición, comparados entre ambos programas de calibración, los rangos de calibración a 1 sigma y 2 sigmas, añadiendo la media de la Calibración a.C. Se incluyen también en ella los resultados de calibración de dichas fechas a 1 sigma y a 2 sigmas y los intervalos de la fecha calibrada correspondientes a las probabilidades totales de $68 \%$ (1 sigma) y 95\% (2 sigmas.) así como la probabilidad porcentual de cada una de esas áreas.

\begin{tabular}{|c|c|c|c|c|c|c|}
\hline Muestra /tumba & Edad C-14 BP & $\%$ Area & $\begin{array}{l}\text { Rango calib. } \\
\text { a.C. BETA }\end{array}$ & $\begin{array}{l}\text { Rango calib } \\
\text { a. C. CALIB }\end{array}$ & $\begin{array}{l}\text { Probabilidad } \\
\text { en cada área }\end{array}$ & $\begin{array}{l}\text { Fecha media } \\
\text { Cal. A.C. }\end{array}$ \\
\hline \multirow[t]{2}{*}{$\begin{array}{l}\text { BBETA.290576 } \\
\text { C3G13T3 } \\
\end{array}$} & $2380 \pm 40$ & $68(1 \sigma)$ & $\begin{array}{l}490-460 \\
420-400\end{array}$ & $\begin{array}{l}510-434 \\
428-397\end{array}$ & $\begin{array}{l}0,680555 \\
0,319445\end{array}$ & $\begin{array}{ll}\text { BETA } 445 \\
\text { CALIB } 453\end{array}$ \\
\hline & & $95(2 \sigma)$ & $\begin{array}{l}720-700 \\
540-390\end{array}$ & $\begin{array}{l}741-689 \\
663-648 \\
549-386\end{array}$ & $\begin{array}{l}0,092416 \\
0,019947 \\
0,887636\end{array}$ & \\
\hline \multirow[t]{2}{*}{$\begin{array}{l}\text { BETA } 290577 \\
\text { C3G14T2 }\end{array}$} & $2500 \pm 40$ & $68(1 \sigma)$ & $\begin{array}{l}770-720 \\
700-540\end{array}$ & $\begin{array}{l}767-731 \\
691-660 \\
651-544\end{array}$ & $\begin{array}{l}0,199937 \\
0,170955 \\
0,629102\end{array}$ & $\begin{array}{l}\text { BETA } 655 \\
\text { CALIB } 656\end{array}$ \\
\hline & & $95(2 \sigma)$ & $\begin{array}{l}790-490 \\
460-420\end{array}$ & $\begin{array}{l}790-505 \\
492-490 \\
462-450 \\
441-417 \\
\end{array}$ & \begin{tabular}{|l|l}
0,96488 \\
0,000867 \\
0,011055 \\
0,023199 \\
\end{tabular} & \\
\hline \multirow[t]{2}{*}{$\begin{array}{l}\text { BETA } 290579 \\
\text { C5G10T2 }\end{array}$} & $2060 \pm 30$ & $68(1 \sigma)$ & $100-40$ & $\begin{array}{l}155-137 \\
113-39 \\
7-5\end{array}$ & $\begin{array}{l}0,12935 \\
0,84895 \\
0,0217 \\
\end{array}$ & $\begin{array}{l}\text { BETA } 70 \\
\text { CALIB } 80\end{array}$ \\
\hline & & $95(2 \sigma)$ & $170-10$ & $169 \mathrm{BC}-2 \mathrm{AD}$ & 1 & \\
\hline \multirow[t]{2}{*}{$\begin{array}{l}\text { BETA } 290580 \\
\text { C5T4 }\end{array}$} & $2240 \pm 30$ & $68(1 \sigma)$ & $\begin{array}{l}380-350 \\
290-220\end{array}$ & $\begin{array}{l}381-353 \\
292-230 \\
218-214 \\
\end{array}$ & $\begin{array}{l}0,301402 \\
0,672355 \\
0,026243\end{array}$ & $\begin{array}{l}\text { BETA } 300 \\
\text { CALIB } 300\end{array}$ \\
\hline & & $95(2 \sigma)$ & \begin{tabular}{|l|}
$390-340$ \\
$330-200$ \\
\end{tabular} & $\begin{array}{l}390-345 \\
323-205\end{array}$ & $\begin{array}{l}0,281221 \\
0,718779 \\
\end{array}$ & \\
\hline \multirow[t]{2}{*}{$\begin{array}{l}\text { BETA } 290581 \\
\text { C5T5 }\end{array}$} & $2370 \pm 40$ & $68(1 \sigma)$ & $410-400$ & $\begin{array}{l}509-437 \\
422-393\end{array}$ & $\begin{array}{l}0,636351 \\
0,363649\end{array}$ & $\begin{array}{l}\text { BETA } 405 \\
\text { CALIB } 451\end{array}$ \\
\hline & & $95(2 \sigma)$ & $530-390$ & $\begin{array}{l}733-690 \\
661-650 \\
545-382 \\
\end{array}$ & $\begin{array}{l}0,069056 \\
0,0119 \\
0,919045\end{array}$ & \\
\hline \multirow[t]{2}{*}{$\begin{array}{l}\text { BETA } 290582 \\
\text { C5T8 }\end{array}$} & $2350 \pm 30$ & $68(1 \sigma)$ & $410-390$ & $\begin{array}{l}482-467 \\
415-386 \\
\end{array}$ & $\begin{array}{l}0,111817 \\
0,888183 \\
\end{array}$ & $\begin{array}{l}\text { BETA } 400 \\
\text { CALIB } 400 \\
\end{array}$ \\
\hline & & $95(2 \sigma)$ & $410-390$ & $512-382$ & 1 & \\
\hline \multirow[t]{2}{*}{$\begin{array}{l}\text { BETA } 290583 \\
\text { C5T9 }\end{array}$} & $2540 \pm 30$ & $68(1 \sigma)$ & $\begin{array}{l}790-750 \\
680-670 \\
610-600\end{array}$ & $\begin{array}{l}794-749 \\
687-666 \\
642-591 \\
577-567 \\
\end{array}$ & \begin{tabular}{|l|}
0,409673 \\
0,190648 \\
0,339099 \\
0,060581 \\
\end{tabular} & $\begin{array}{l}\text { BETA } 665 \\
\text { CALIB } 680\end{array}$ \\
\hline & & $95(2 \sigma)$ & $\begin{array}{l}800-720 \\
700-540\end{array}$ & $\begin{array}{l}801-705 \\
695-539\end{array}$ & \begin{tabular}{|l|}
0,385614 \\
0.614386
\end{tabular} & \\
\hline
\end{tabular}

Tabla 1.- Parámetros básicos de las dataciones comparadas (BETA, IntCal04 y CALIB, IntCal 09) y media calibrada. 
El primer análisis es la transformación simple de la fecha media BP a BC sin calibrar añadiendo el rango de incertidumbre. El cálculo ofrece el siguiente resultado, ordenado en la exposición de fecha más antigua a más reciente: C5T9: $2540 \pm$ 30: 590 a.C.; C3G14T2: 2500 40: 550; C3G13T3: $2380 \pm 40$ : 430; C5T5: 2370 \pm 30 : 420; C5T8:

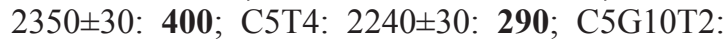
2060 \pm 30 : 110. Las fechas así obtenidas nos acercan a la datación tradicional de estas necrópolis. Así hubiéramos afirmado que las fechas de utilización de la necrópolis abarcan desde comienzos del s VI hasta finales del s. II a.C., con dos muestras datadas en el Celtibérico Antiguo, tres ya en el s. V, es decir Celtibérico Pleno y una en el Tardío, según la nomenclatura al uso.

La calibración de las fechas absolutas de la Prehistoria Reciente, como es sabido, ofrece datos casi siempre más antiguos que las fechas originales. $\mathrm{Al}$ estudiar la distribución de probabilidades en cada área para la fecha calibrada según los datos de CALIB observamos que hay dos muestras que tienen un total de concentración en sus valores calibrados, es decir, el 100\% a dos sigmas: Beta 290582 (tumba C5T8) en el intervalo de 512 - 382 a.C. y Beta 290579 (tumba C5G10T2) en el intervalo 169 a.C. - 2 d.C. En el primer caso el $89 \%$ de probabilidades a 2 sigmas cae en el intervalo 415 - 386 a.C. En el segundo, con un $84,8 \%$ de probabilidades en el mismo porcentaje de área, se sitúa en 113 - 39 a.C. (vid. Fig. 14).

La muestra Beta 290581 (C5T5) tiene un 92\% de probabilidades a 2 sigmas en el intervalo 545-382
a.C. La correspondiente a la tumba C3G13T3 (Beta 290576) alcanza el 88,7\% a dos sigmas entre 549 y 386 a.C. A 1 sigma el $68 \%$ de probabilidades se concentra entre los valores 510 y 434 a.C. C3G14T2 (Beta 290577) arroja un intervalo de $790-505$ con el $96,4 \%$ de probabilidades, también a dos sigmas. A 1 sigma, el $62,9 \%$ de probabilidades se sitúa entre 651 y 544 a.C. C5T4 (Beta 290580) tiene la concentración de probabilidades en un $71,8 \%$, a dos sigmas en 323 - 205 a.C. Por último C5T9 (Beta 290583), tiene una probabilidad de $61,4 \%$ en el intervalo 695 - 539, a 2 sigmas. Es obvio que la dispersión notable de las probabilidades calibradas se debe a las mesetas de la curva de calibración.

De este modo, el orden cronológico de las dataciones de las incineraciones así obtenido sería el siguiente: $790-505$ a.C (C3G14T2 / BETA 290577), 695 -539 a.C. (C5T9/BETA 290583), 549 -386 (C3G13T3/ BETA 290576), 545 -382 (C5T5/ BETA 290581), 512-382 (C5T8 /BETA 290582) en este caso con un $100 \%$ de probabilidades, 323 -205 a.C. (C5T4/ BETA 290580 ) y 169 a.C.- 2 d.C. (C5G10T2/ BETA 290579) también con un 100\% de probabilidades a 2 sigmas.

A excepción de la primera fecha, que analizaremos más adelante, cuyo valor inicial resulta anómalo en función de la tipología de la urna y de algunos elementos de ajuar, los dos siguientes, C5T9 y C3G13T3, tienen un solapamiento de fechas que coinciden parcialmente con C5T8 y que las hacen congruentes. El intervalo de C5T4 coincide parcialmente con nuestra apreciación sobre la tipología de la urna, decorada con pintura negra, concretándose

Atmospheric data from Stuiver et al. (1998); OxCal v3.9 Bronk Ramsey (2003); cub r.4 sd:12 prob usp[chron]

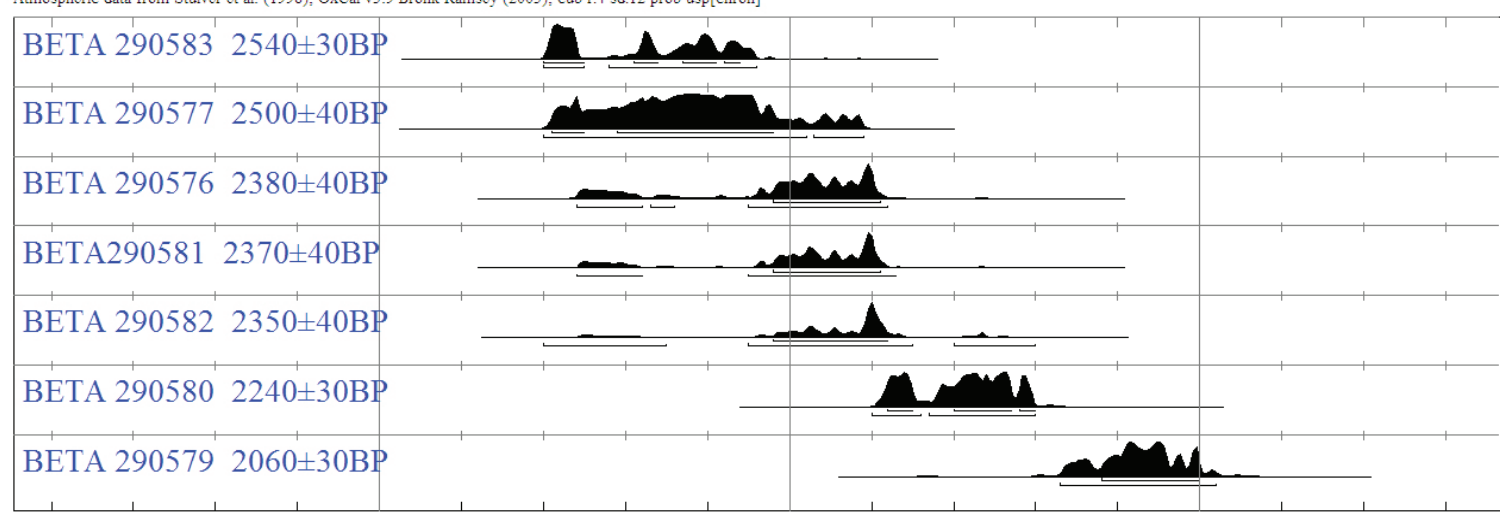

$1000 \mathrm{CalBC}$

$500 \mathrm{CalBC}$

$\mathrm{CalBC} / \mathrm{CalAD}$

Calibrated date

Figura 14.- Representación conjunta de la calibración de las dataciones de radiocarbono obtenidas en las siete tumbas celtibéricas de El Inchidero (programa OxCal v.3.9). 
ahora la fecha a mediados del s. IV a.C. Por último la tumba C5G10T2 puede sin dificultad, por las características especificadas en los capítulos precedentes, fechar la fase final del uso de la necrópolis.

Por último aplicaremos, como es la norma en el caso de distribuciones irregulares (Vega 2007: 185), el valor central del intervalo de probabilidad de la calibración a 1 sigma (de los resultados de las dos calibraciones) para establecer la comparativa de la serie obtenida de fechas. Asumimos que la probabilidad de esa fecha concreto es muy pequeña, pero la consideramos representativa, como ocurre siempre con los valores medios, de la distribución en su conjunto, a efectos comparativos de unas dataciones con otras y siempre en comparación con otros criterios de índole exclusivamente arqueológica. De ello obtenemos la siguiente sucesión cronológica indicando en primer lugar el resultado sobre los datos de IntCal 09 y en segundo lugar los de IntCal 04:

C5T9 (Beta 290583): 680 / 665 a.C.; C3G14T2 (Beta 290577): 656 / 655 a.C.; C3G13T3 (Beta 290576): 453 / 445 a.C.; C5T5 (Beta 290581): 451 / 405 a.C.; C5T8 (Beta 290582): 400 / 400 a.C.; C5T4 (Beta 290580): $300 /$ 300a.C. y C5G10T2 (Beta 290579): 80 / 70 a.C.

Relacionando los tres niveles de análisis que hemos aplicado, resulta de interés comprobar que existen cinco muestras cuyas diferencias tanto en el método tradicional para la obtención de fecha no calibrada como en su calibración ofrecen fechas similares: C3G13T3: 430 no calibrada y 453, la media ponderada a 1 sigma ; C5T5: 420 y 451; C5T8: 400 y 400; C5T4: 290 у 300 у C5G10T2: 110 y 87, todas a.C. Sin embargo existen dos fechas cuya calibración efectivamente las envejece en un siglo: C5T9: 590 no calibrada y 680, media ponderada a un sigma y C3G14T2: 550 y 656 en los mismos supuestos. Recordemos que la primera tenía el $61,4 \%$ de probabilidades a 2 sigmas (CALIB) de situarse en el intervalo 695 - 539 a.C. y que en C3G14T2, la probabilidad más alta, $96,4 \%$ se halla en el rango de calibración de 790 a 505; a 62,9\% el rango calibrado a dos sigmas se reduce al intervalo de 651 -544 a.C.

La primera conclusión que obtenemos es que, efectivamente, solo un número alto de muestras pueden ofrecernos cierta seguridad temporal, siempre con una resolución en torno a un siglo. La segunda es que, como hemos indicado antes, dado que un resultado radiocarbónico no constituye, hoy por hoy, una fecha concreta calendárica sino solo una aproximación estadística (Fábregas 1992), las dataciones nos parecen satisfactorias por cuanto corroboran la secuencia evolutiva de la necrópolis previamente establecida por criterios arqueológicos.

\section{Conclusiones}

Para lo que hemos considerado primera fase, es decir la caracterizada por alineaciones de tumbas, se han obtenido dos fechas radiocarbónicas que superan nuestra expectativa de cronología. Una de ellas es la correspondiente a la tumba C5T9 (Beta 290583), como se recordará con uno de los ajuares más numerosos y variados. El mayor porcentaje de probabilidad calibrada a dos sigmas, $61,4 \%$, corresponde al intervalo 695 - 539 a.C., con una media ponderada a un sigma de 680 a.C. La segunda muestra es la extraída de la tumba C3G14T2 (Beta 290577), cuyo mayor valor de probabilidad a dos sigmas, 96,4\% lo obtiene en el rango calibrado 790 - 505 a.C. La media ponderada a un sigma es de 656 a.C. De ambas fechas se deduce en una primera valoración que la cronología obtenida para esta primera fase se halle alrededor de 680 / 656 a.C., es decir la primera mitad del s. VII a.C.

Resulta extraño que las dos fechas -y nada apunta a que sean erróneos los resultados- se desvíen de las últimas dataciones obtenidas en otros yacimientos relacionados por las urnas y los ajuares que los acompañan. En la primera tumba el estudio tipológico de sus materiales no fue concluyente. La pieza más moderna sería la fíbula anular que correspondería al modelo 6B de Argente (1994: 68) fechada desde el s. V a la segunda mitad del III. Y no podemos olvidar en el extremo contrario el puñal de empuñadura maciza tipo que se fecha entre el s. VII y el VI a.C. Aún si aceptáramos la fecha más baja del rango calibrado a un sigma, lo que es arbitrario, intentando aproximarnos a las cronologías tradicionales de la tipología, la fecha sería 539 a.C En el segundo caso las urnas se fechan entre el Celtibérico Pleno y el s. I a.C. Sus elementos de tocado o soportes tienen una amplia cronología en sus marcos superiores que son los que ahora nos interesan.

Si relacionamos estas datos con otros yacimientos que nos han ofrecido cronologías absolutas, nuestras fechas llevan a La Torre de Codes, que tiene una fecha calibrada de 669 a.C. (Arenas 1999: 199). Sin embargo el horizonte cultural de este yacimiento es claramente más antiguo. Otro caso es Herrería III (Cerdeño y Sagardoy 2007) con una cronología absoluta del primer tercio del s. VIII a la primera mitad del VII a.C. (Vega 2007: 185). Sin embargo algunos rasgos de esta necrópolis en su fase III, como la presencia de armas, entre ellas espadas, puntas de lanza, regatones o soportes.... así como las primeras cerámicas a torno decoradas con pintura roja que nosotros hemos documentado en $\mathrm{C} 4$, permiten plantear la posibilidad de que nuestra primera fase sea subsecuente o coincida con los momentos finales de aquella. En este caso podríamos 
aceptar finales del s.VII cal.a.C o principios del VI cal.a.C. para el comienzo de esta fase, con un final hacia mediados del V cal.a.C. Esta última fecha vendría dada por las dataciones obtenidas para una segunda fase si convenimos que no hubo interrupción en el uso de la necrópolis, problema que no podemos analizar aquí. La trascendencia de esta asignación cronológica vendría determinada porque estas tumbas, y lo que sabemos del poblado, muestran las características que atribuimos al Celtibérico Pleno. El poblado de la necrópolis es inusualmente grande para esas fechas, pues, como hemos indicado tiene una superficie de 2,5 Ha. ¿Implicaría esto un poblado de mayor rango y con mayores y más antiguas relaciones con la costa? Las armas completamente dobladas que se recogieron en la banda arrasada por las máquinas, deberían adscribirse tipológicamente a los momentos intermedios de esta fase, así como las tumbas C3G13T1 y C3T2, estratigráficamente inferiores a C3G14T2. Queda pendiente de otros estudios definir si entre esta fase y la segunda hubo ruptura o continuidad cultural.

Respecto a las tumbas de la segunda fase, tenemos la tumba C3G13T3 con rango de calibración de 510 -397 y una media calibrada de 453 a.C.; la tumba C5T5 está en el rango 545 - 383 con un $92 \%$ de probabilidades a dos sigmas y tiene una media calibrada de 451; C5 T8 tiene un 100\% de probabilidades sobre el rango a dos sigmas en el intervalo 512 - 382, con media ponderada de 400 . Por último la tumba C5T4, con un rango de $323-205$, tiene una media ponderada en 300 . Las tres primeras fechas tienen en sus rangos de calibración una llamativa similitud en horquillas calendáricas (510-397, $545-383$ y $512-382$ ). Obviamente la continuidad que define una fase viene demostrada por el solapamiento de las fechas, lo que nos da la seguridad de datación de este segundo periodo. Esta valoración asigna a esta fase una cronología desde mediados del s. V hasta el final del IV cal. a.C.

La fase segunda, que establecimos a priori, está caracterizada por la reordenación de la necrópolis en calles de estelas entre otros aspectos, y a ella corresponden las tumbas que ahora analizamos. La C3G13T3 confirma esta apreciación dejando a las cuestiones estratigráficas (Fig. 4) ya expuestas el resto. Por otro lado, confirmaría que es ahora cuando se colocó la estela en la C5T8, rompiendo la urna, gesto que podría haber rejuvenecido la fecha radiocarbónica. De ser esto así, podríamos explicar la estratigrafía incluyendo esta tumba en la fase anterior y en consecuencia obtener una fecha más antigua para los elementos de su ajuar. Todo ello, tumba, estratigrafía y ajuares serían así coherentes.

Otro de los rasgos que atribuíamos a esta etapa es que los ajuares metálicos de armas o soportes o tocados desaparecen, lo que se fecha a mediados de s. IV por la mayoría de los autores. Aquí sin embargo parece ocurrir a partir de mediados de $\mathrm{s}$. V cal. a.C. De ser así apuntaría a desarrollos locales desiguales, algo lógico por otro lado.

A una tercera fase correspondería la tumba C5G10T2 (Beta 290579). Como puede verse en la Tabla 1, tiene un $100 \%$ de probabilidades de que su fecha se sitúe en el rango 169 a.C. - 2 d.C. (Intcal 09) calibrada a dos sigmas. La media ponderada sobre los valores a un sigma es 80 a.C. No obstante, por afán de ser rigurosos hemos de señalar que el desfase de la fecha con respecto a la continuidad de la necrópolis pudo deberse a un fenómeno de crioturbación que rejuveneciera su fecha sí, por ejemplo, existió encima de ella un depósito de restos carbonizados ocasionada por una ofrenda ritual de la que, por superficial, pudo no haberse conservado ningún resto.

El hiato cronológico entre esta fecha y las anteriores puede deberse a que solo contamos con una datación para la que consideramos última fase de la necrópolis. De hecho es posible que las tumbas C5G10T2 y C3G13T4 sean de las últimas tumbas depositadas de esta fase tercera, lógicamente en la parte excavada. El intervalo de fechas concuerda con la época en que, tras la marcha de Graco, esta zona junto con el Alto Tajo y el Alto Duero permanecía aún fuera del control romano (García Riaza 2006: 91).Otra explicación igualmente convincente para una fecha del s. I a.C. es que las tumbas fueran depositadas cuando la necrópolis estaba ya fuera de uso. Ambas tumbas muestran una clara intención de situarse, precisamente, sobre otras, tal vez por razones familiares. La apreciación estratigráfica, la morfología tumbal y la tipología de los materiales apuntan más a una sucesión que a una ruptura cultural entre las fases segunda y tercera si consideramos que a esta misma fase por razones estratigráficas corresponden la jarra trilobulada o las copas de pie aparecidas en el último nivel, que pueden ser fechadas, como se ha indicado, a partir del s.III a.C. De este modo la tercera fase de la necrópolis abarcaría desde el comienzo del s. III hasta por lo menos el siglo II cal a.C.

A modo de resumen hay que destacar el importante hecho de que las fechas radiocarbónicas retrasan aproximadamente un siglo el comienzo de lo que hemos venido considerando Celtibérico Pleno, entendido como el momento en que las características de esta cultura aparecen claramente definidas. Las fechas absolutas obtenidas para la primera fase de Aguilar de Montuenga resultan coherentes con los resultados de Herrería III, entendido éste como una fase antecedente de nuestro primer nivel. 
Igualmente hemos comprobado que la sucesión de fases que habíamos establecido a priori basado en la estratigrafía y los estudios del material ha sido corroborada por las dataciones absolutas, resolviendo y precisando las fechas de algunas tumbas, pero retrasando en general la cronología. Podemos deducir que el proceso interno de la cultura celtibérica está adquiriendo unos ejes cronológicos acordes con la complejidad cultural que contiene su origen y su evolución. Queda abierta la revisión que compare estos datos con las culturas relacionadas con la celtibérica, en particular las de la costa levantina, coloniales e ibérica, con atención preferente a los modelos e incidencia del fenómeno colonial en el interior, siempre a partir de las fechas radiocarbónicas integradas en el razonamiento arqueológico y, en particular, la reconsideración de los ritmos evolutivos internos de la cultura celtibérica y todos aquellos procesos de estímulo externo y aculturación, entendidos como adopción de determinados rasgos o innovaciones, que ahora se intuye más inmediata e incluso más brusca de lo que antes creíamos.

\section{Notas}

1. La excavación arqueológica fue dirigida conjuntamente con A. Ruiz, de la empresa Arquetipo S.L., a quien debo también la informatización de las planimetrías.

2. Algunos ajuares fueron extraídos en bloque por su frágil estado de conservación, en particular los procedentes de C4. Hasta la fecha no ha podido procederse a su restauración, por lo que una vez completada más adelante esperamos poder ampliar el estudio de la necrópolis.

\section{REFERENCIAS BIBLIOGRÁFICAS}

Aguilera y Gamboa, E. (1909): El Alto Jalón. Madrid.

Aguilera y Gamboa, E. (1916): Las necrópolis ibéricas. Madrid.

Almagro Gorbea, M.; Lorrio Alvarado, J. A. (1987): Materiales cerámicos de una necrópolis celtibérica de Molina de Aragón (Guadalajara). Wad-al-Hayara, 14: 269-279.

Arenas Esteban, J. A. (1990): La necrópolis protohistórica de La Cerrada de los Santos (Aragoncillo, Guadalajara). Algunas consideraciones en torno a su contexto arqueológico. En Burillo 1990: 93-99.

Arenas Esteban, J.A. (1999): El inicio de la Edad del Hierro en el Sector Central del Sistema Ibérico. En Arenas y Palacios 1999: 191-211.

Arenas, J.A.; Martínez Naranjo, J.P. (1993 - 1995): Poblamiento prehistórico en la serranía Molinesa: "El Turmielo" de Argoncillo (Guadalajara). Kalathos, 13-14: 89-141.

Arenas, J. A.; Palacios, M. V. (eds.) (1999): El origen del Mundo Celtibérico. Actas sobre los encuentros sobre el origen del mundo celtibérico. Molina de Aragón.

Argente Oliver, J. L. (1977): La necrópolis celtibérica de `El Altillo“" en Aguilar de Anguita (Guadalajara). Resultados de la campaña de excavación de 1973. Wad-al-Hayara, 4: 99-141.

Argente Oliver, J. L. (1994): Las fibulas de la Edad del Hierro en la Meseta Oriental. Valoración tipológica, cronológica y cultural. Excavaciones Arqueológicas en España, 168, Madrid.

Argente, J. L.; Díaz, A.; Bescós, A. (2000): Tiermes V. Carratiermes. Necrópolis celtibérica. Campañas 1977, 1986 - 1991. Arqueología en Castilla y León, 9, Memorias.

Arlegui, M.: (1992): El yacimiento celtibérico de "Castilmontán”, Somaén (Soria): el sistema defensivo. $2^{\circ}$ Simposium de Arqueología Soriana, Excma. Diputación Provincial de Soria: 495-513.

Arlegul Sánchez, M. (en prensa): La necrópolis de El Inchidero. Aguilar de Montuenga, Soria. En Burillo en prensa.

Baquedano Beltrán, I (1990): Elementos relacionados con el caballo en tumbas inéditas de la Osera (zona II). En Burillo 1990: 279-304.

BARRIL, M.; QuesAdA, F. (2006): El caballo en el mundo prerromano. Actas de la reunión celebrada en el M.A.N. el 2 de Marzo de 2005, Museo Arqueológico Nacional, Madrid.

Bowman, S. (1990): Radiocarbon dating. British Museum, Londres.

Burillo, F. (coord.) (1990): Necrópolis Celtibéricas. II Simposio sobre los Celtíberos. Institución Fernando el Católico, Zaragoza.

Burillo, F. (coord.) (1995): El poblamiento celtibérico. III Simposio sobre los Celtiberos. Institución Fernando el Católico, Zaragoza. 
Burillo, F. (coord.) (2006): Segeda y su contexto histórico. Entre Catón y Nobilior (195 al 153 a.C.). Fundación Segeda de Estudios Celtibéricos, Zaragoza.

Burillo, F. (Coord.) (en prensa): Nuevos hallazgos. Nuevos descubrimientos. VII Simposio sobre los Celtíberos 20-22 de Marzo de 2012, Daroca.

Cabré Aguiló, J. (1930): Excavaciones en la necrópolis celtibérica del Altillo de Cerropozo, Atienza (Guadalajara). M.J.S.E.A. 105, Madrid: 5-40.

Cabré Agulló, J. (1939-1940): La caetra y el scutum en Hispania durante la Segunda Edad del Hierro. Boletín del Seminario de Arte y Arqueología, 6: 57-83.

CABrÉ de MorÁn, E. (1990): Espadas y puñales de las necrópolis celtibéricas. En Burillo 1990: 205-244.

Cabré de Morán, E.; Morán CABré, J. A. (1975): Dos tumbas datables de la necrópolis de Alpanseque (Soria). Archivo de Prehistoria Levantina, XIV: 123-137.

Cabré de Morán, E.; Morán Cabré, J. A. (1978): Fíbulas hispánicas con apéndice caudal zoomorfo. Boletín de la Asociación Española de Amigos de la arqueología, 9: 8-22.

Cabré de Morán, E.; Morán Cabré, J. A. (1982): Ensayo cronológico de las fíbulas con esquema de La Tène en la Meseta Hispánica. Boletín de la Asociación Española de Amigos de la Arqueología, 15: 4-27.

Cerdeño, M. L. (1976): La necrópolis celtibérica de Valdenovillos (Guadalajara). Wad-al-Hayara, 3: 5-26.

Cerdeño, M. L. (1978): Informes sobre campañas de excavación en Guadalajara (1977). Prados Redondos (Sigüenza). Wad-Al-Hayara, 5.

Cerdeño, M. L. (1979): La necrópolis céltica de Sigüenza (Guadalajara). Wad-al Hayara, 6: 49-75.

Cerdeño, M. L. (1981): La necrópolis de Molina de Aragón (Guadalajara). Campos de urnas en el este de la Meseta. Wad-al-Hayara, 8: 9-73.

Cerdeño, M. L.; García Huerta, R.; Arenas Esteban, J. A. (1995): El poblamiento celtibérico en la Región del Alto Tajo y Alto Jalón. En Burillo 1995: 157-183.

Cerdeño, M. L.; Pérez, J. L.; Cabanes, E. (1993-1995): Secuencia cultural de "El Ceremeño" (Guadalajara). Kalathos, 13 -14: 61-88.

Cerdeño, M. L.; Sagardoy, T. (2007): La necrópolis celtibérica de Herrería III (Guadalajara). Estudios Celtibéricos, 4 Fundación Segeda y Junta de Comunidades de Castilla-La Mancha, Guadalajara.

Cerdeño, M.L. et al. (en prensa): Ámbar en la meseta oriental durante el Bronce Final: yacimientos locales e importaciones bálticas. Trabajos de Prehistoria 69(2).

Cuadrado Díaz, E. (1968): Excavaciones en la necrópolis de Riba de Saelices. Excavaciones Arqueológicas en España, 60, Madrid.

CuAdrado E. (1987): La necrópolis Ibérica de "El Cigarralejo" (Mula, Murcia). Bibliotheca Praehistorica Hispana, XXIII, Madrid.

Cundrado, E. (1989) La panoplia ibérica de 'El Cigarralejo' (Mula, Murcia). Murcia

DíAz DíAz, A. (1976): La cerámica de la necrópolis celtibérica de Luzaga (Guadalajara), conservada en el Museo Arqueológico nacional. Revista de Archivos, Bibliotecas y Museos, LXXIX, 2: 397-489.

FÁbregas VAlcarce, R. (1992): ¿Tercera revolución del Radiocarbono? Una perspectiva arqueológica. Boletín del Seminario de Estudios de Arte y Arqueología, 58: 9-22.

Fernández Galiano, D.; Valiente, S; Pérez Herrero, E. (1982): La necrópolis de la Primera Edad del Hierro de Prados Redondos (Sigüenza, Guadalajara), campaña 1974. Wad-al-Hayara, 9: 9-36.

García Huerta, M. R. (1980): La necrópolis de la Edad del Hierro en La Olmeda (Guadalajara). Wad-al-Hayara, 7: 9-33.

García Huerta, M. R (1990): La Edad del Hierro en la Meseta Oriental: El Alto Jalón y el Alto Tajo. Tesis Doctoral Universidad Complutense 50/90. Madrid.

García Huerta, R.; Antona, V. (1992): La necrópolis celtibérica de La Yunta (Guadalajara). Campañas 1984 1987. Excavaciones arqueológicas en Castilla-La Mancha, Madrid.

Garcia RiazA, E. (2006): La expansión romana en la Celtiberia. En Burillo 2006: 81-94.

GillesPIE, R. (1984): Radiocarbon user's handbook. Oxford.

IGME (1973): Mapa metalogenético de España. Instituto Geológico y Minero de España, Ministerio de Industria, Madrid.

Jimeno, A. (1996): Numancia: Relación necrópolis- poblado. Archivo Español de Arqueología, 69: 57-76 
Lorrio Alvarado, A.J. (1990): La Mercadera (Soria): Organización social y distribución de la riqueza en uan necrópolis celtibérica. En Burillo, 1990: 39-50.

Lorrio Alvarado, A. J. (2005): Los Celtíberos. Bibliotheca Archaeologica Hispana, 25, Real Academia de la Historia, Madrid.

Madroñero, A. y Arlegui, M. (1992): Objetos de hierro y restos metalúrgicos del yacimiento de Castilmontán (Somaén, Soria). Revista del C.E.N.I.N, C.S.I.C Madrid.

Martínez Naranjo, J. P. (1997): El inicio del mundo celtibérico en el interfluvio Jalón-Mesa. Complutum, 8: 161-182.

Moret, P.; Quesada SAnz, F. (eds.) (2002): La guerra en el mundo ibérico y celtibérico (ss. VI-II a. C.), Collection de la Casa de Velázquez, 78, Madrid.

Paz Escribano, M. de (1980): La necrópolis céltica de El Atance (Guadalajara). Wad-al-Hayara, 7: 35-57.

Quesada SAnz, F. (1993): Soliferrea de la Edad del Hierro en la Península Ibérica. Trabajos de Prehistoria, 50: $159-183$.

QuESADA SANZ, F. (1997): El armamento ibérico. Estudio tipológico, geográfico, funcional, social y simbólico de las armas en la Cultura Ibérica (siglos VI-I a.C.). Monographies Instrumentum, Éditions Monique Merggoil, Montagnac.

Quesada SAnz, F. (2002): Armas y arreos de caballo en la protohistoria peninsular. Problemas de documentación y líneas de investigación prioritarias. En Moret y Quesada 2002: 1-34.

Quesada SAnz, F. (2005): El gobierno del caballo en la antigüedad clásica con especial referencia al caso de Iberia. Bocados, espuelas y la cuestión de la silla de montar, estribos y herraduras. Gladius, XXV: 97-150.

ReIMER, P.J. et. al. (2009): IntCal 09 and Marine09 Radiocarbon Age Calibration Curves, 0 -50,000 Years cal BP. Radiocarbon, 51 (4): 1111-1150.

Requejo Osorio, J. (1978): La necrópolis celtibérica de Carabias (Guadalajara). Wad al Hayara, 5: 49-62.

Ruiz-Gálvez, M. L. (1990): Propuesta para el estudio e interpretación de las necrópolis sin armas. En Burillo 1990: 343-347.

SchÜLE, W. (1969): Die Meseta-Kulturen der Iberischen Halbinsel, I-II. Berlín.

SIEMCALSA (1997): Mapa Geológico y Minero de Castilla y León. Valladolid.

Stuiver, M.; Pearson, G.W. (1986): High-precision calibration of the radiocarbon time scale, AD 1950-500 BC. Radiocarbon, 28-2b: 805-838.

STUIVER, M. et al. (1998): High-precision radiocarbon age calibration for terrestrial and marine samples. Radiocarbon, 40:1127-1151.

Taracena Aguirre, B. (1932): Excavaciones en la provincia de Soria. Memorias de la Junta Superior de Excavaciones y Antigüedades, nº 119, Madrid.

Vega Toscano, L.G. (2007): Dataciones radiocarbónicas de la fase III de la necrópolis de Herrería (Guadalajara). En Cerdeño y Sagardoy 2007: 183-186.

Waterbolk, H.T. (1971): Working with radiocarbon dates. Proceedings of the Prehistoric Society, 37: 5-33.

Waterbolк, H.T. (1983): Ten guidelines for the archaeological interpretation of radiocarbon dating. ${ }^{14} \mathrm{C}$ and $\mathrm{Ar}$ chaeology, Council of Europe, Strasbourg: 17-27. 